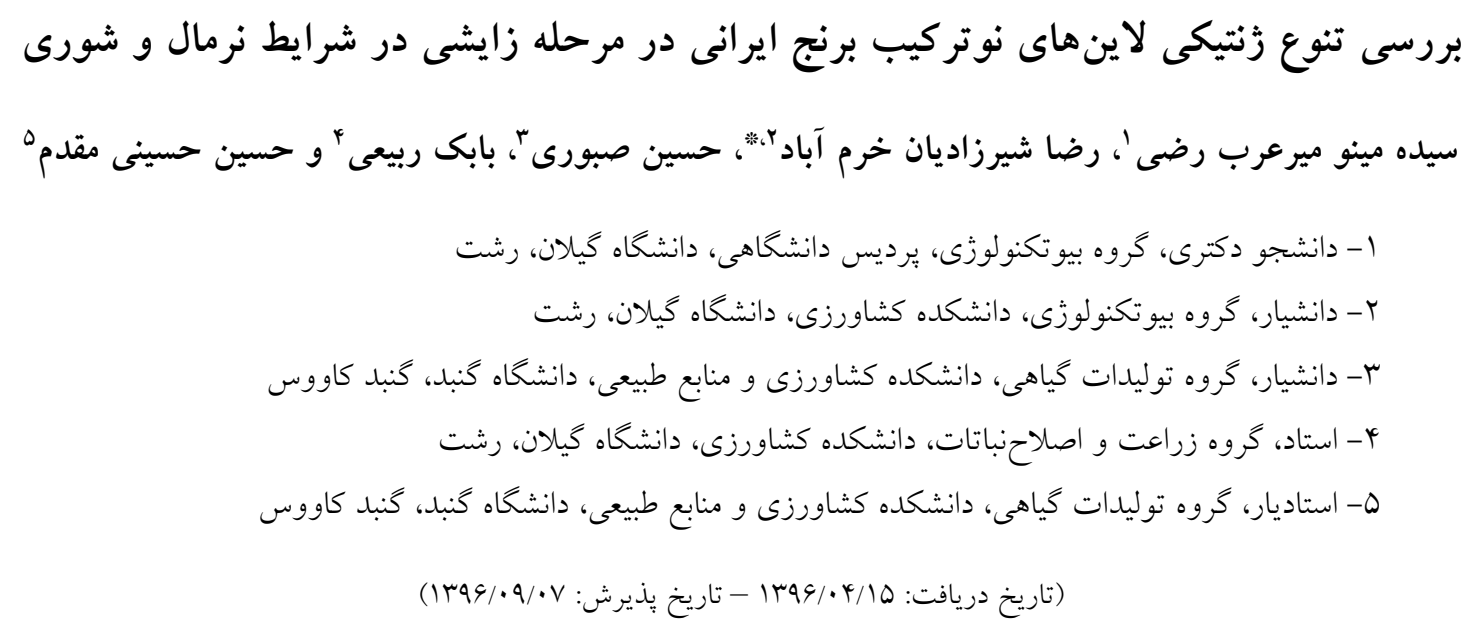

شورى يك عامل محدودكننده مهم در توليد بيشتر كياهان و از جمله برنج است. با توجه به محدود بودن سطح زير كشت،

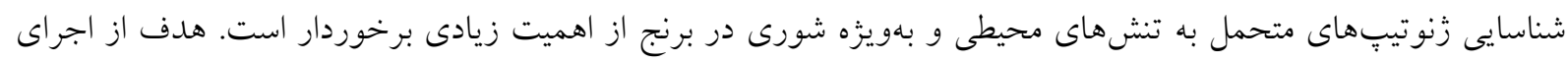

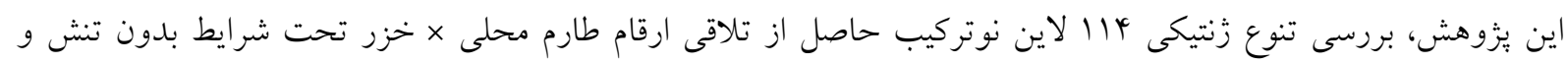

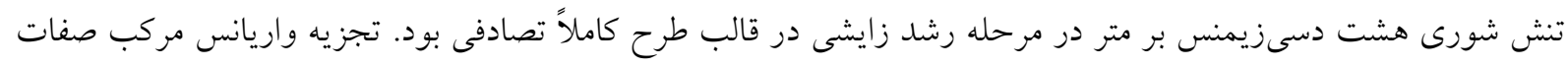

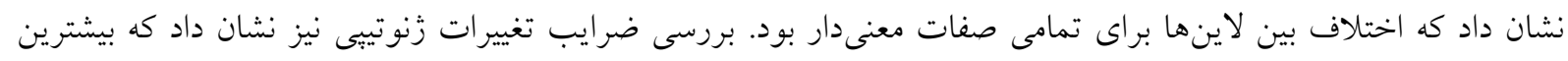

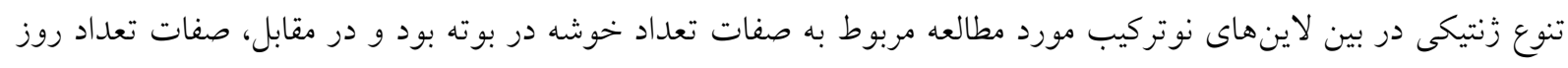

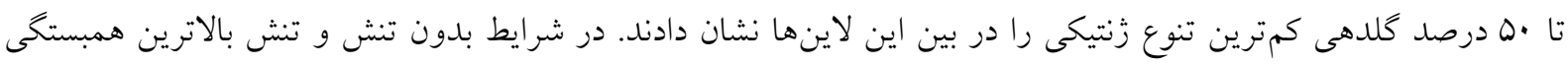

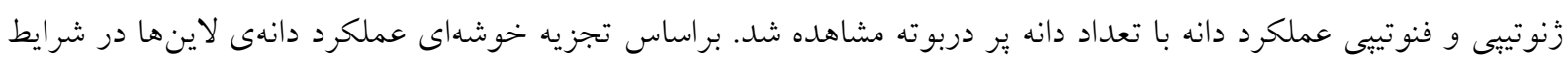

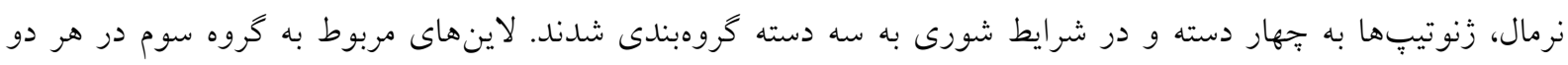

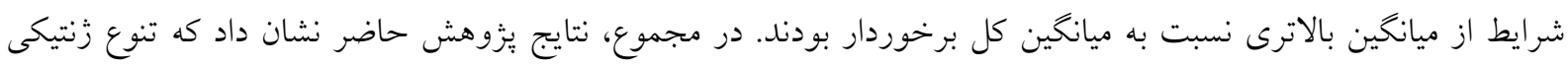

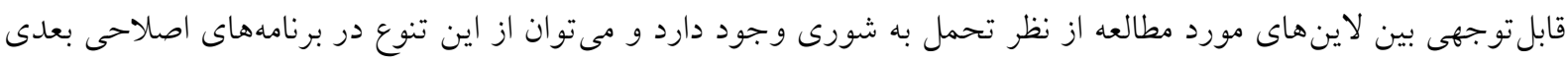

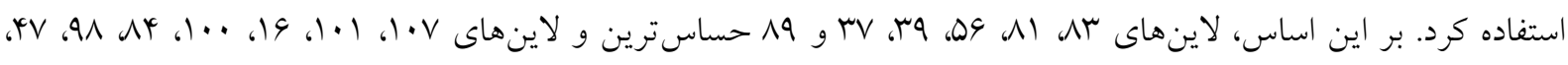

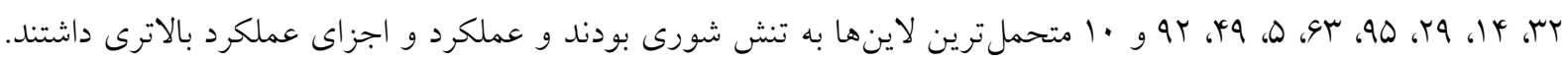

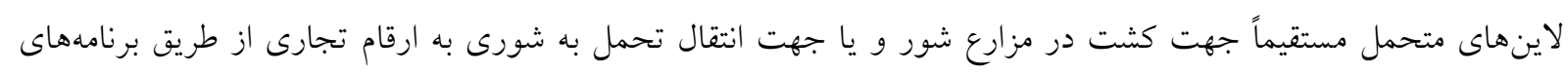
اصلاحى آينده بيشنهاد مىشوند. وازگًان كليدى: برنج، تجزيه به عاملها، تجزيه خوشهاى، شورى، همبستى 
متحمل مىشود (Ghomi et al., 2013a,b). تنش شورى در مرحله توليدمثلى بيش از مرحله رشد رويشى عملكرد را كم كرده و تحت تأثير قرار مىدهد ( Abdmishani and

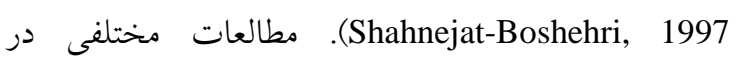
مرحله زايشى روى برنج با اعمال تنش شورى انجام شده

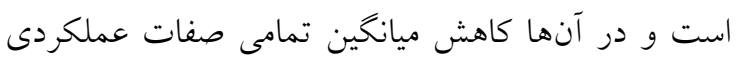
كزارش شده است ( Sabouri and Biyabani, 2009; Akhtar et al., 2010; Aref and Ebrahimi, 2012; Bakhsh-Balouchzaehi and Kiani, 2013; Ghomi et و (al., 2013a,b; Kordrostami et al., 2017

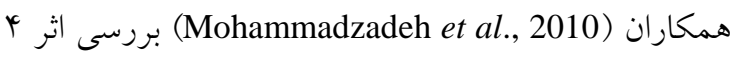

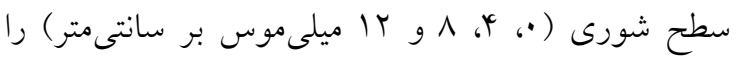
روى † زُنوتيب برنج در مرحله زايشى بررسى كردند.

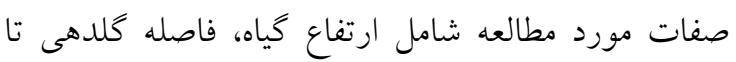
رسيدن، تعداد يُنه مؤثر، طول خوشه اوليه، طول بقيه

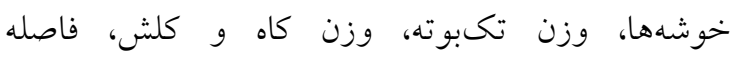

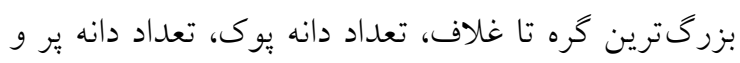
زيست توده كل بود. شورى بر روى تمامى صفات اثر برد معنى دارى داشت. تجزيه واريانس براى عملكرد و اجزاى عملكرد تفاوت معنى دار بين زنوتيبها ران نشان داد. ميردار منصورى و همكاران (Mirdar-Mansouri et al., 2014) نيز مطالعهاى روى اثر دو سطح تنش شورى بر عملكرد و اجزاى عملكرد آب زنوتيب برنج انجام دادند. نتايج تجزيه

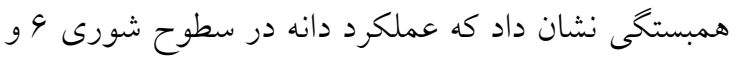
•ا دسىزيمنس بر متر همبستخى بسيار معنىدار يا تعداد

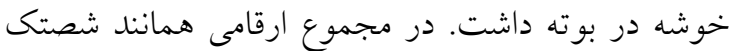

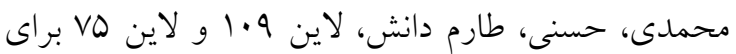
صفات مربوط در مرحله رشد زايشى از نظر تحمل به شورى برتر از ساير ارقام مورد بررسى بودند. رشيد و

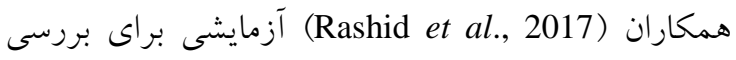

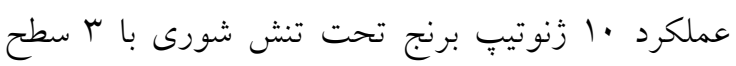

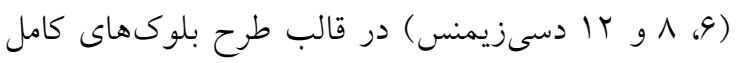

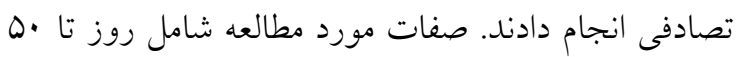

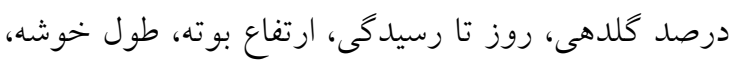

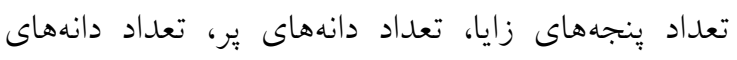

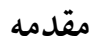

برنج از خانواده Gramineae بوده و جنس Oryza sativa شامل •r گ گونه متفاوت مى باشد كه تنها دو گونه آن شامل Oryza glaberrima L. و Oryza sativa L. و برنج آفريقايى) زراعى هستند. اين دو گونه دييلوئيد

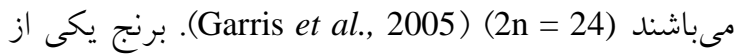
منابع اصلى براى بخش بزرگى از مردم جهان محسوب مىشود. ·9 درصد برنج جهان در آسيا توليد مىشود. ايران بيستمين كشور توليد كننده برنج جهان با ميانخين

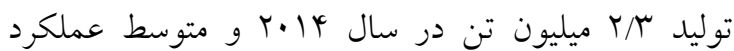
א/ ب تن در هكتار مىباشد (FAO, 2016).

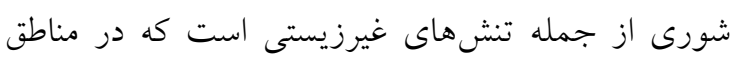

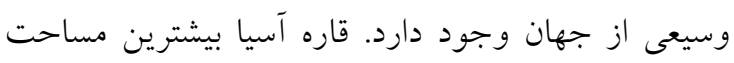

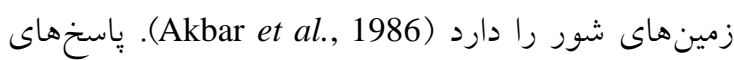

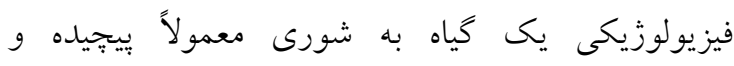
جندوجهى است. ياسخ گياهان به شورى شامل دو مرحله اصلى است؛ مرحله اول واكنشهاى مستقل يونى اندام هوايى كه در عرض تجند دقيقه تا جند روز رخ مى دهد و بهنظر مىرسد مربوط به حساسيت و سيخنالدهى $\mathrm{Na}^{+}$

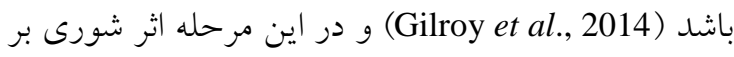
ميزان آب مهم است و منجربه بسته شدن روزنهها و جلوگيرى از رشد و گسترش برگها مىشود. مرحله دوم، واكنشهاى وابسته به يون شورى است كه طى يك دوره طولانى (روز تا هفتها) ايجاد مىشود و شامل تشكيل يونها با غلظتهاى سمى در بخشهاى هو ايى بلويزه در برگهاى قديمى است كه منجربه ييرى زودرس برگها و

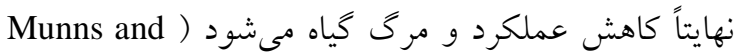

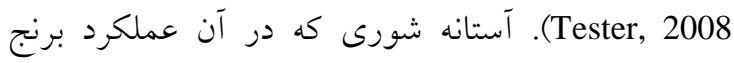
بهصورت كلى تحت تأثير قرار مى گيرد، سه دسىزيمنس دله بر متر مىباشد (Maas and Hoffmann, 1977). اثرات شورى بر كياه برنج در مراحل مختلف رشد متفاوت است.

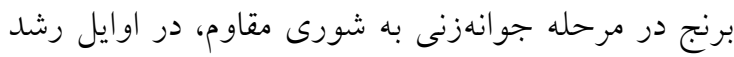
نشاء بسيار حساس، در زمان رشد رويشى مقاوم، در زمان

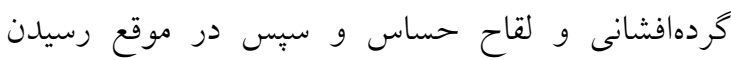


خاك با جذب آب در داخل ظرفها بايدار شد. سطح آب

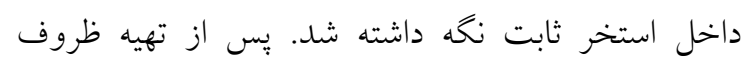

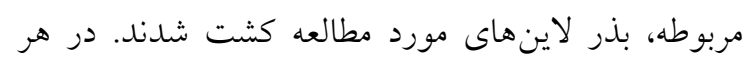

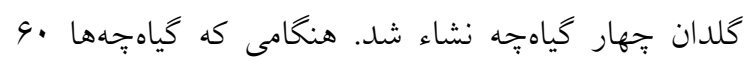

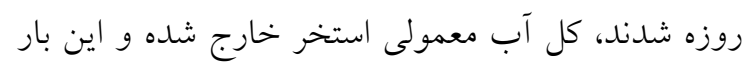

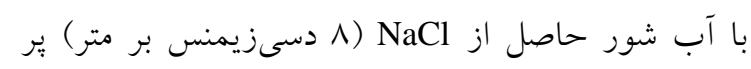

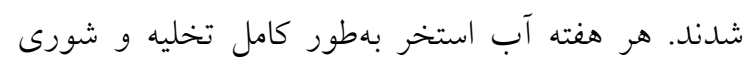

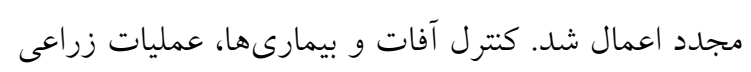
و تغذيهاى براى هر دو تيمار انجام شد. صفات مختلف وند

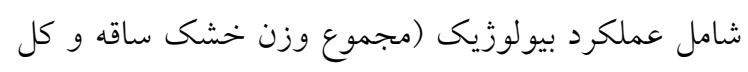
خوشه ها در يك بوته) برحسب گرم، ارتفاع بوته در بور روز

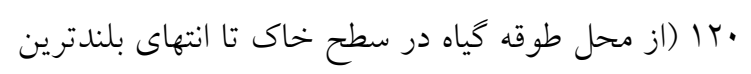

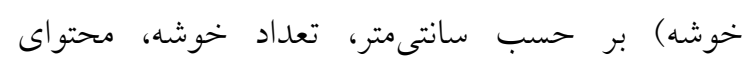
كلروفيل برى در سه نقطه از هر برى در اطراف رخبرى اصلى (توسط دستخاه كلروفيل متر دستى مدل SPAD502

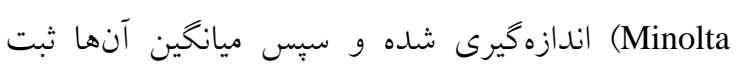

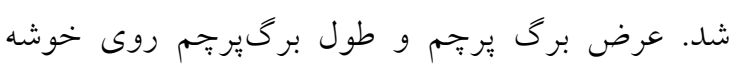

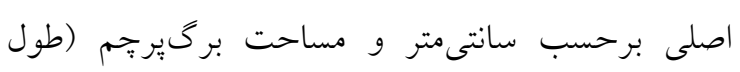

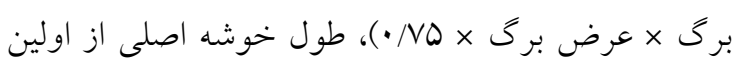

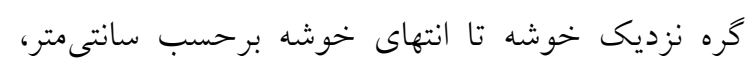
طول خروج خوشه از غلاف (فاصله نزديكترين خره

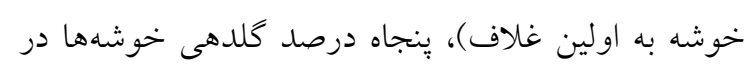

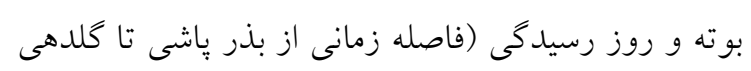

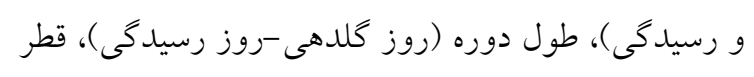

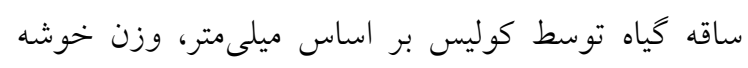

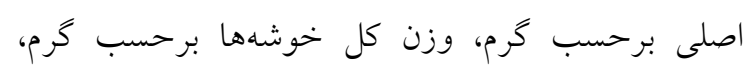

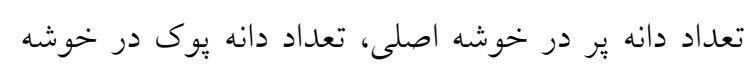

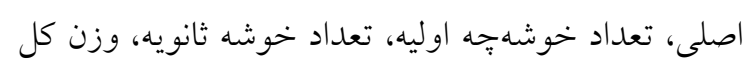

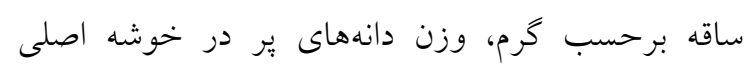

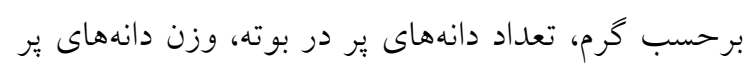

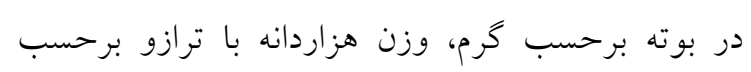

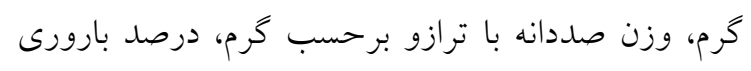

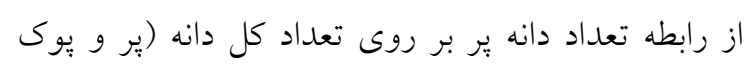

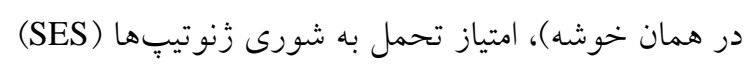

يوك، درصد بارورى، وزن هزاردانه و عملكرد خوشه بود.

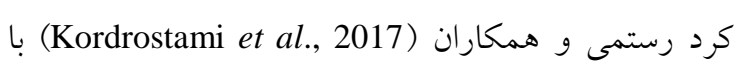

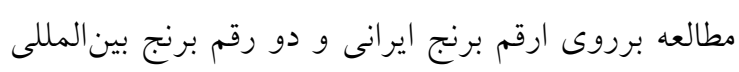

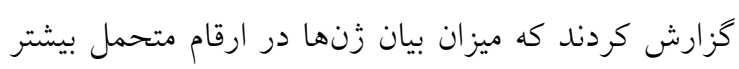

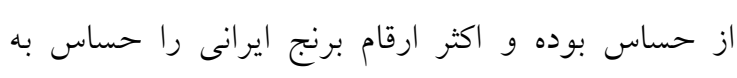
شورى دانستند. هدف از تحقيق حاضر ارزيابى تنوع زنتيكى لاينهاى

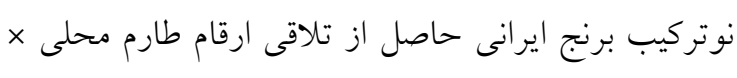

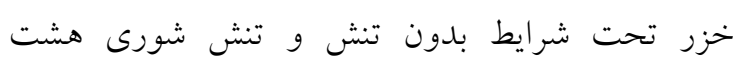

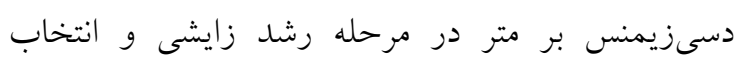

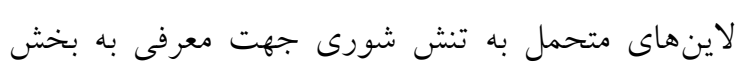

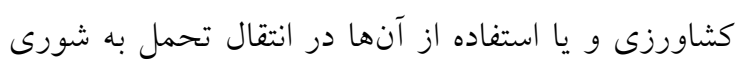
به رقمهاى تجارى از طريق برنامهاى اصلاحى آينده بود.

\section{مواد و روشها}

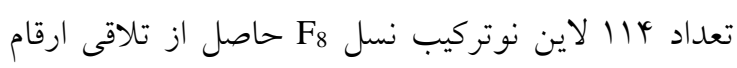

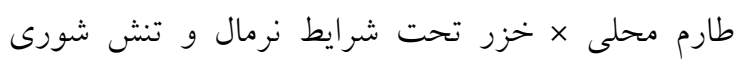

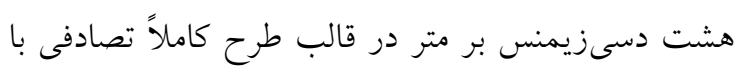
جهار تكرار به روش گريخور و همكاران ( Gregorio et (al., 1997

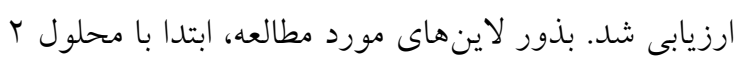

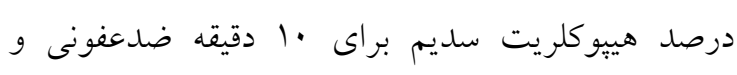

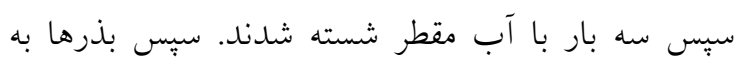

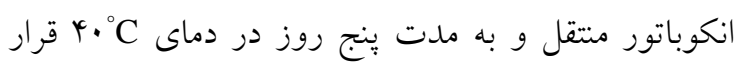
كرفتند تا عمل جوانهزنى انجام شد ( Ebrahimi et al.,

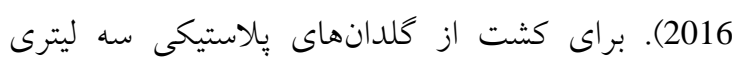

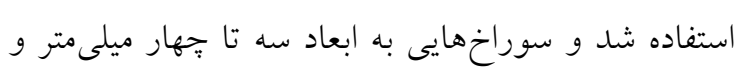

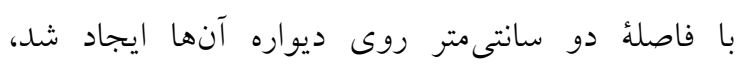
بهصورتى كه بالاترين سوراخها، حداقل سه سانتى متر از

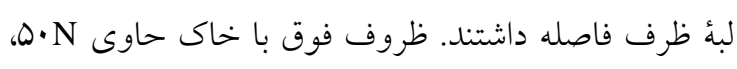

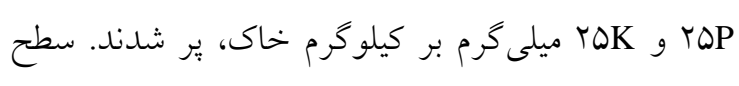

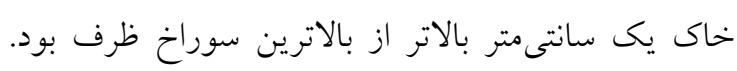

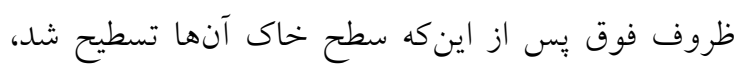

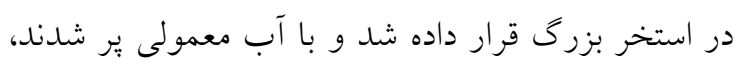

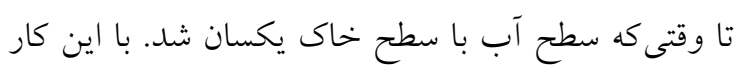


مقايسه سطوح تنش شورى براى صفات مورد بررسى: اختلاف دو محيط بدون تنش و تنش شورى براى كليه

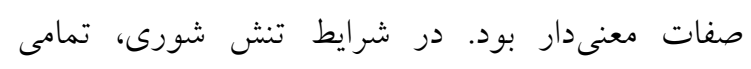

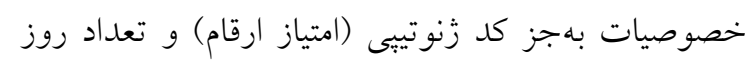

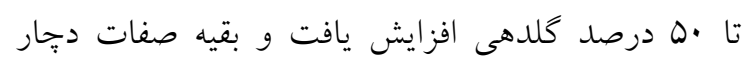

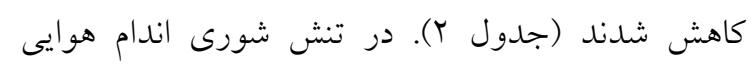
نسبت به ريشه كاهش بيشترى داشته زيرا مساحت و و

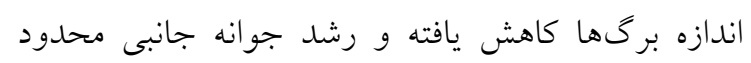

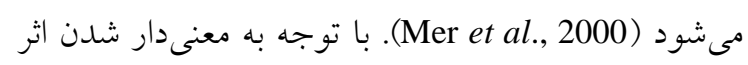
متقابل لاين در تنش براى صفات مورد بررسى، اين

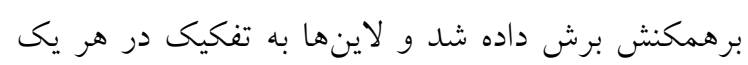
از شرايط نرمال و تنش شورى مورد مقايسه قرار كرفتند. ضرايب همبستخى فنوتيى و زنوتييى ميان صفات:

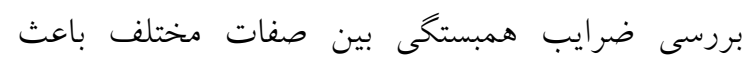

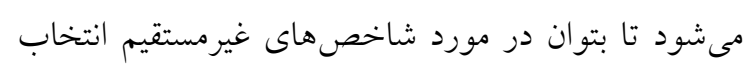
و حذف صفات غيرمستقيم بهطور دقيق تصميم گيرى نمود

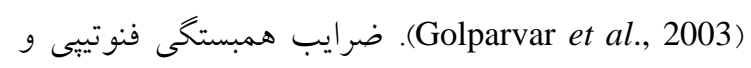

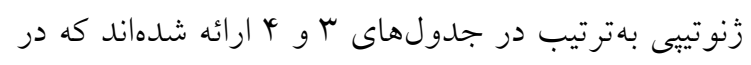

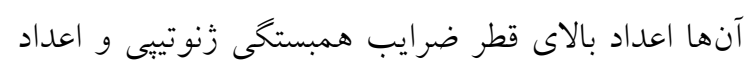

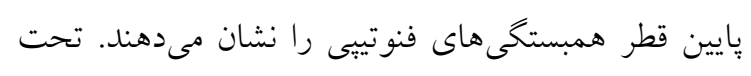

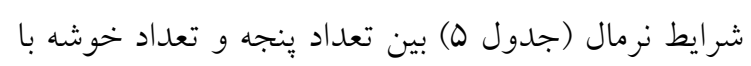

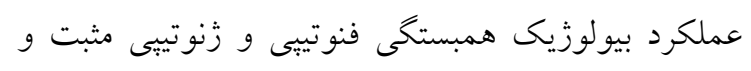

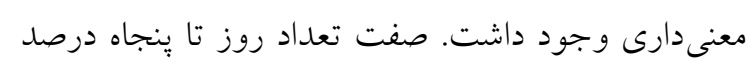
كلدهى و روز تا رسيدكى نيز با تعداد خوشه و و تعداد

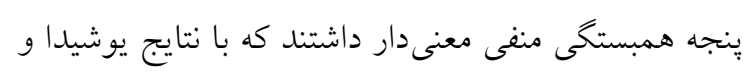

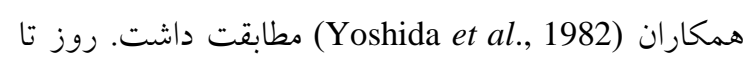

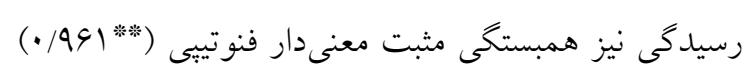

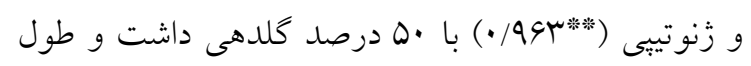

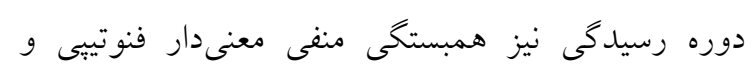

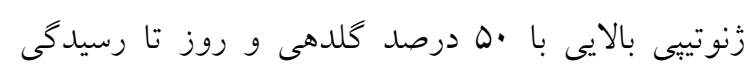

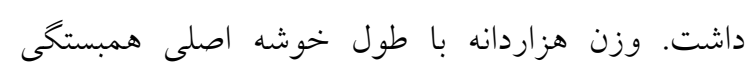
مثبت فنوتيى داشت كه با نتايج ساويتا و همكاران (Savitha and Usha-Kumari, 2015)

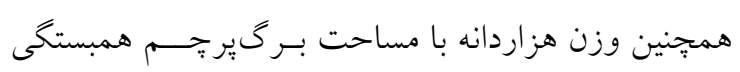

با استفاده از سيستم نمره دهى 9-1 صورت يذيرفت Gregorio et al., 1997)

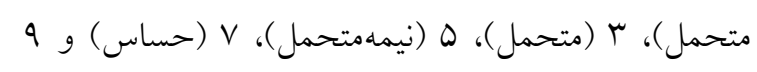

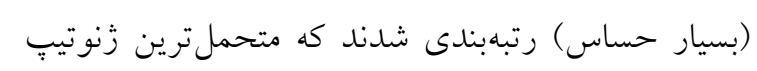
رتبه ا و حساسترين رتبه 9 را به خود اختصاص دادند.

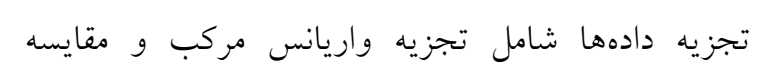

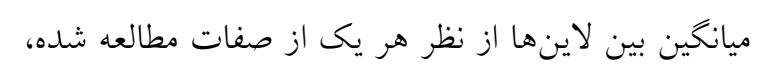
همجنين ضرايب همبستكى زنتيكى و فنوتييى با استفاده از

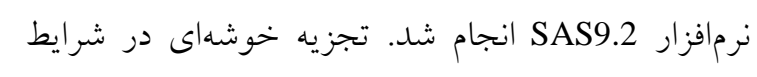

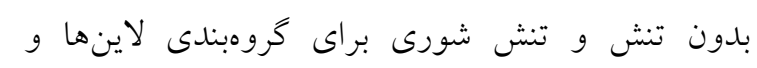

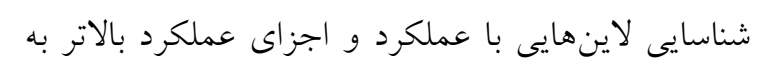
ويزه تحت تنش شورى، با استفاده از نرمافزار

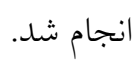

نتايج و بحث

تجزيه واريانس مركب صفات مورد بررسى: نتيجه

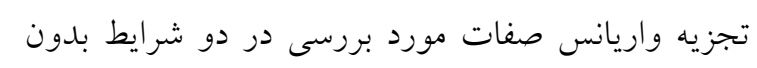
تنش و تنش شورى، اختلاف بين لاينها را براى كليه

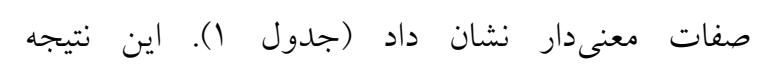

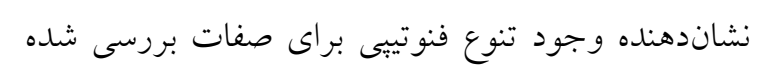

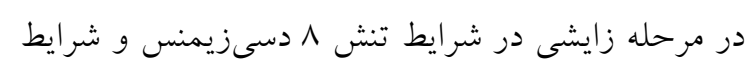

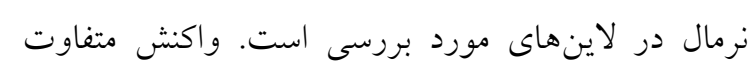

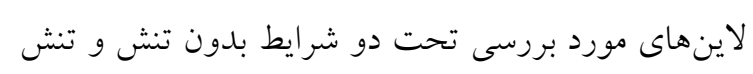
شورى موجب شد كه اثر متقابل لاين × تنش براى كليه

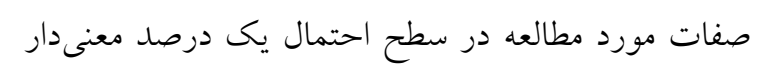

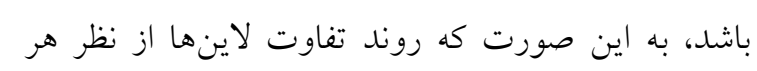
صفت در دو سطح نرمال و تنش تفاوت داشت. معنىدار

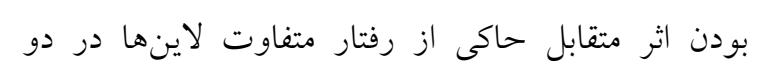

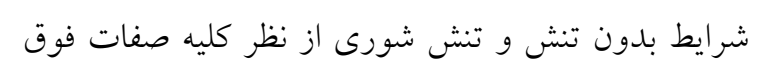

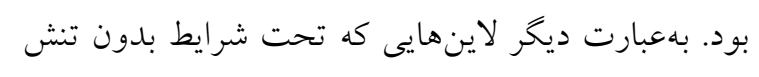

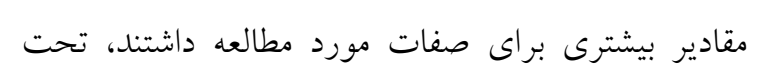

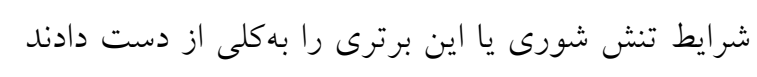

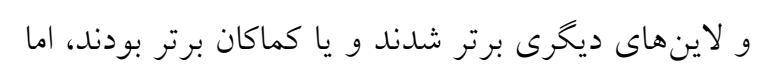

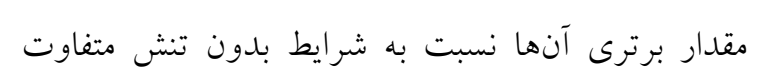
بود. 
جدول ا- تجزيه واريانس صفات مورد بررسى

Table 1. Analysis of variance of studied traits

\begin{tabular}{|c|c|c|c|c|c|c|c|c|c|c|c|c|c|c|}
\hline \multirow{2}{*}{ منابع تغييرات } & \multirow{2}{*}{ S.O.V } & \multirow{2}{*}{ درجه آزادى (d.f) } & \multicolumn{12}{|c|}{ ميانخين مربعات (Mean of square) } \\
\hline & & & BY & $\mathrm{PH}$ & PNP & TNP & FLA & MPL & PELSH & DF & $\mathrm{DM}$ & DP & SD & TPW \\
\hline تنش شورى & Salinity stress & 1 & $6991.17^{* *}$ & $182027.28^{* *}$ & $150.65^{* *}$ & $43.71^{* * *}$ & $22481.03^{* *}$ & $9297.24^{* *}$ & $7025.30^{* * *}$ & $10678.37 *$ & $1349.36^{* * *}$ & $16115.13^{* *}$ & $157.70^{* * *}$ & $1425.06^{* * *}$ \\
\hline خطا 1 & Error 1 & 6 & 0.853 & 50.18 & 1.52 & 0.859 & 56.05 & 7.04 & 0.877 & 29.59 & 11.02 & 16.41 & 0.738 & 0.046 \\
\hline لاين & Line & 113 & $101.87^{* *}$ & $2377.78^{* * *}$ & $12.42^{* *}$ & $10.99^{* *}$ & $301.68^{* *}$ & $88.77^{* *}$ & $142.13^{* *}$ & $389.03^{* * *}$ & $191.45^{* *}$ & $55.32^{* *}$ & $6.06^{* *}$ & $9.74^{* *}$ \\
\hline لاين × تنش & Salinity stress $\times$ Line & 113 & $53.62^{* *}$ & $860.30^{* *}$ & $5.47^{* *}$ & $6.61^{* *}$ & $197.87^{* *}$ & $58.93^{* *}$ & $97.78^{* *}$ & $176.18^{* * *}$ & $107.41^{* *}$ & $28.74^{* *}$ & $4.37^{* *}$ & $6.69^{* *}$ \\
\hline خطbا & Error 2 & 684 & 1.02 & 64.12 & 0.66 & 0.7 & 31.33 & 6.08 & 1.125 & 1.44 & 10.23 & 0.59 & 0.42 & 0.145 \\
\hline \multirow{2}{*}{\multicolumn{3}{|c|}{ 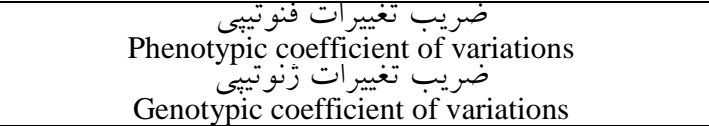 }} & 10.76 & 7.55 & 25.44 & 22.53 & 25.23 & 11.66 & 17.4 & 1.57 & 3.3 & 3.69 & 13.05 & 18.08 \\
\hline & & & 10 & 6.09 & 24.4 & 21.2 & 23.69 & 11.2 & 15.7 & 1 & 2.56 & 3.6 & 11.85 & 16.5 \\
\hline
\end{tabular}

ادامه جدول

Continued from Table 1

\begin{tabular}{|c|c|c|c|c|c|c|c|c|c|c|c|c|c|c|c|}
\hline \multirow{2}{*}{ منابع تغييرات } & \multirow{2}{*}{ S.O.V } & \multirow{2}{*}{ درجه آزادى (d.f) } & \multicolumn{13}{|c|}{ ميانخين مربعات (Mean of square) } \\
\hline & & & MPW & NFG & NPB & NSB & SDW & FGWP & TGNP & TGW & $100 \mathrm{GW}$ & $1000 \mathrm{GW}$ & FP & GC & $\mathrm{B}$ \\
\hline تنش شورى & Salinity stress & 1 & $229.79^{* *}$ & $339520.60^{* *}$ & $818.52^{* *}$ & 7 & $2164.46^{* *}$ & * $213.05^{* *}$ & $1318372^{* *}$ & $825.90^{* *}$ & $137.42^{* *}$ & $13825.52^{* * *}$ & $239086.19^{* *}$ & $2647.93^{* *}$ & $11199.45^{* *}$ \\
\hline خطا 1 & Error 1 & 6 & 0.023 & 77.05 & 1.42 & 5.6 & 0.987 & 0.031 & 15.38 & 0.0053 & 0.00039 & 0.04 & 21.99 & 1.1 & 0.846 \\
\hline لاين & Line & 113 & $1.50^{* *}$ & $2941.60^{* *}$ & $16.45^{* *}$ & $154.50^{* *}$ & $* 71.21^{* *}$ & $1.42^{* *}$ & $11709.21^{\text {*** }}$ & $6.27^{* * *}$ & $1.11^{* *}$ & $111.56^{* *}$ & $2466.36^{* *}$ & $9.92^{* *}$ & $149.33^{* *}$ \\
\hline لاين× تنش & Salinity stress $\times$ Line & 113 & $1.08^{* *}$ & $1817.27^{* *}$ & $15.78^{* *}$ & $104.67^{* *}$ & $41.74^{* *}$ & $1.02^{* *}$ & $7939.70^{* *}$ & $4.79^{* *}$ & $0.83^{* *}$ & $82.86^{* *}$ & $1538.42^{* *}$ & $9.92^{* *}$ & $84.514^{* *}$ \\
\hline خططا r & Error 2 & 684 & 0.032 & 24.79 & 1.52 & 5.89 & 0.79 & 0.014 & 20.37 & 0.011 & 0.001 & 0.156 & 14.44 & 0.402 & 1.39 \\
\hline \multirow{2}{*}{\multicolumn{3}{|c|}{ 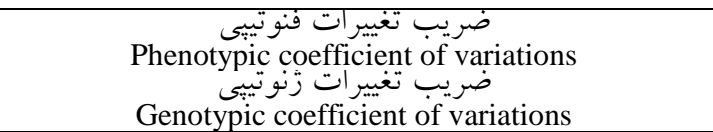 }} & 18.68 & 14.68 & 16.42 & 23.91 & 12.16 & 16.18 & 7.39 & 7.85 & 2.16 & 2.02 & 9.93 & 23.37 & 9.49 \\
\hline & & & 17.9 & 13.5 & 14.6 & 20.9 & 11.3 & 16 & 6.67 & 7.25 & 2.11 & 2 & 8.84 & 22.33 & 8.4 \\
\hline
\end{tabular}

ns, * and **: Non-significant, significant at 5 and 1\% probability level, respectively

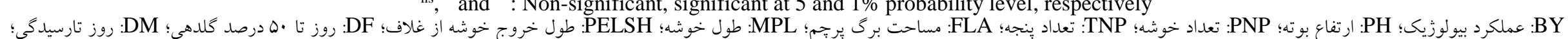

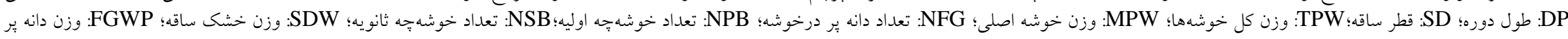

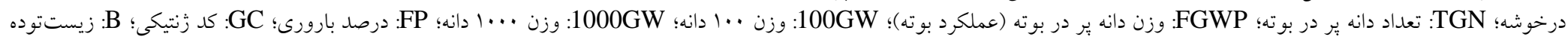

BY: Biological yield; PH: Plant height; PNP: Panicle number in plant; TNP: Tiller number in plant; FLA: Flag leaf area; MPL: The main panicle length; PELSH: The panicle exit length from sheath; DF: Days to 50\% flowering; DM: Daye's to maturity; DP: During the period; SD: Stem diameter; TPW: Total panicle weight; MPW: The main panicle weight; NFG: Number of filled grain in panicle; NPB: Number of primary branches; NSB: Number of Secondary branches; SDW: Stem dry weight; FGWP: Filled grain weight in panicle; TGN: Total grain number in plant; FGWP: Filled grain weight in plant (grain yield); $100 \mathrm{GW:} 100$ grain weight; $1000 \mathrm{GW}$ : 1000 grain weight; FP: Fertility percent; GC: Genotypic code; B: Biomass 


\begin{tabular}{|c|c|c|c|}
\hline \multirow{2}{*}{ صفت } & \multirow{2}{*}{ Traits } & \multicolumn{2}{|c|}{ شرايط (Conditions) } \\
\hline & & 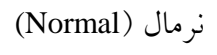 & تنش شورى (Salt stress) \\
\hline عملكرد بيولوزيك (كرم) & Biological yield (gr), BY & $12.21^{\mathrm{a}}$ & $6.59^{\mathrm{b}}$ \\
\hline ارتفاع بوته (سانتىمتر) & Plant height $(\mathrm{cm}), \mathrm{PH}$ & $120.04^{\mathrm{a}}$ & $92.03^{\mathrm{b}}$ \\
\hline تعداد خوشه & Panicle number in plant, PNP & $3.57^{\mathrm{a}}$ & $2.83^{\mathrm{b}}$ \\
\hline تعداد ينجه & Tiller number in plant, TNP & $4^{\mathrm{a}}$ & $3.52^{\mathrm{b}}$ \\
\hline مساحت برى ير تِم ( سانتىمترمربع) & Flag leaf area $\left(\mathrm{cm}^{2}\right)$, FLA & $25.27^{\mathrm{a}}$ & $17.12^{\mathrm{b}}$ \\
\hline طول خوشه اصلى ( سانتىمتر) & The main panicle length $(\mathrm{cm})$, MPL & $24.42^{\mathrm{a}}$ & $17.90^{\mathrm{b}}$ \\
\hline طول خروج خوشه از غلاف ( سانتىمتر) & The panicle exit length from sheath $(\mathrm{cm})$, PELSH & $8.78^{\mathrm{a}}$ & $3.40^{\mathrm{b}}$ \\
\hline روز تا •ه درصد كلدهى & Days to $50 \%$ flowering, DF & $72.72^{\mathrm{b}}$ & $79.65^{\mathrm{a}}$ \\
\hline روز تارسيدىى & Daye's to maturity, DM & $98.01^{\mathrm{a}}$ & $95.59^{\mathrm{b}}$ \\
\hline طول دوره & During the period, DP & $25.31^{\mathrm{a}}$ & $16.32^{\mathrm{b}}$ \\
\hline قطرساقه (ميلى متر) & Stem diameter $(\mathrm{mm}), \mathrm{SD}$ & $5.46^{\mathrm{a}}$ & $4.55^{\mathrm{b}}$ \\
\hline وزن كل خوشه ها (كرم) & Total panicle weight (gr), TPW & $3.35^{\mathrm{a}}$ & $0.87^{\mathrm{b}}$ \\
\hline وزن خوشه اصلى (كرم) & The main panicle weight (gr), MPW & $1.47^{\mathrm{a}}$ & $0.45^{\mathrm{b}}$ \\
\hline تعداد دانه ير درخوشه & Number of filled grain in panicle, NFG & $53.03^{\mathrm{a}}$ & $14.77^{\mathrm{b}}$ \\
\hline تعداد خوشه پهه اوليه & Number of primary branches, NPB & $8.49^{\mathrm{a}}$ & $6.55^{\mathrm{b}}$ \\
\hline تعداد خوشه جه ثانويه & Number of Secondary branches, NSB & $13.70^{\mathrm{a}}$ & $6.59^{\mathrm{b}}$ \\
\hline وزن خشك ساقه (كرم) & Stem dry weight (gr), SDW & $8.91^{\mathrm{a}}$ & $5.77^{\mathrm{b}}$ \\
\hline وزن دانه ير درخوشه (كَرم) & Filled grain weight in panicle (gr), FGWP & $1.23^{\mathrm{a}}$ & $0.26^{\mathrm{b}}$ \\
\hline تعداد دانه يُر در بوته & Total grain number in plant, TGN & $99.15^{\mathrm{a}}$ & $23.00^{\mathrm{b}}$ \\
\hline وزن دانه بر در بوته (عملكرد بوته) (كرم) & Filled grain weight in plant (grain yield) (gr), FGWP & $2.32^{\mathrm{a}}$ & $0.41^{\mathrm{b}}$ \\
\hline وزن . إنه (خرم) & 100 grain weight $(\mathrm{gr}), 100 \mathrm{GW}$ & $2.34^{\mathrm{a}}$ & $1.56^{\mathrm{b}}$ \\
\hline وزن ... إنه (كرم) & 1000 grain weight $(\mathrm{gr}), 1000 \mathrm{GW}$ & $23.45^{\mathrm{a}}$ & $15.65^{\mathrm{b}}$ \\
\hline درصد بارورى & Fertility percent, FP & $54.43^{\mathrm{a}}$ & $22.03^{\mathrm{b}}$ \\
\hline كد زنتيكى & Genotypic code, GC & $1.00^{\mathrm{b}}$ & $4.42^{\mathrm{a}}$ \\
\hline زيست توده (كرم) & Biomass (gr), B & $15.92^{\mathrm{a}}$ & $8.91^{\mathrm{b}}$ \\
\hline
\end{tabular}

ميانكينها با حروف متفاوت، در سطحاحتمال ه./ با با يكديخر اختلاف معنى دار دارند.

Means with different letters are significantly different at 0.05 probability level. 
معنى دار عملكرد دانه با تعداد خوشهجه اوليه و ثانويه نيز كزارش شد (Hossain et al., 2015). اسلام و همكاران با مطالعه تنوع زنتيكى در سر (Islam et al., 2016)

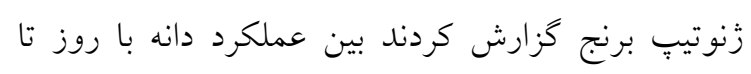

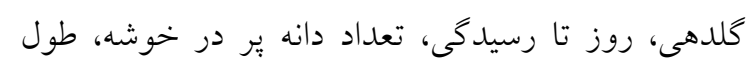

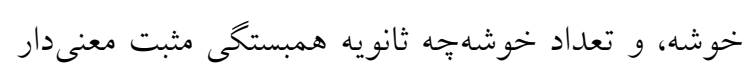

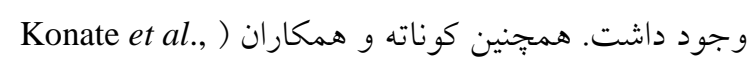

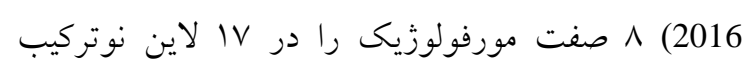
برنج در شرايط نرمال به منظور تنوع زنتيكى مطالعه كردند

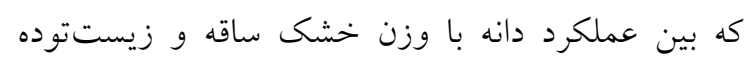

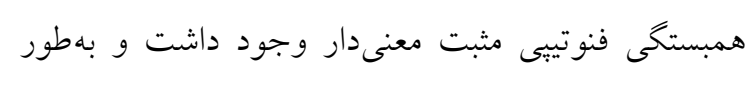
كل اين دو صفت بهعنوان معيارهاى انتخاب براى بهبود عملكرد معرفى شدند.

مطابق جدول شماره 9 براى شرايط تنش شورى صفات

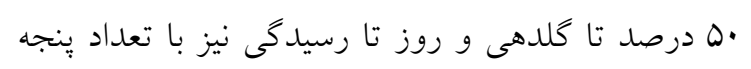

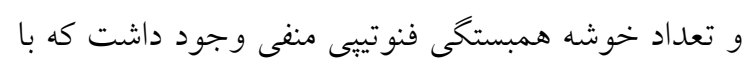
نتايج يوشيدا و همكاران (Yoshida et al., 1982) مطابقت

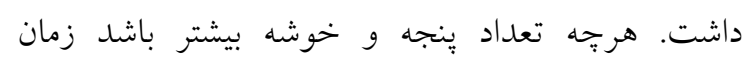
كلدهى و رسيدگى نيز كوتاهتر خواهد شد. وزن ساقه بالاترين همبستخى فنوتييى و زنوتييى را با ارتفاع، تعداد ينجه و وزن كل خوشه ها داشت كه با نتايج محمد زاده و همكاران (Mohammadzadeh et al., 2010) مطابقت داشت. كد زنوتييى نيز با تمامى صفات همبستخى فنوتييى و زنوتييى منفى داشت. همجزنين صبورى و همكاران نشان دادند كه همبستخى بين كد هدين (Sabouri et al., 2008)

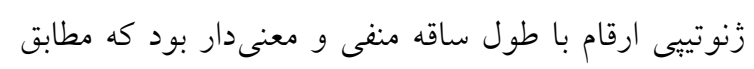

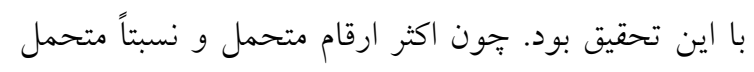
ساقه طويلترى دارند بهتر است در برنامههاى اصلاحى بـ بون

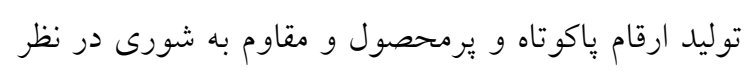

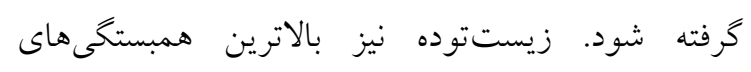

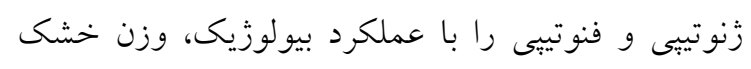

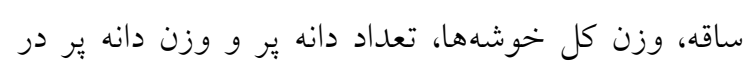

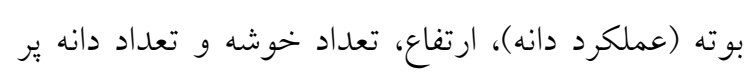
در خوشه داشت. صفت زيست تودهه همبستكى منفى معنى دارى با كد زنوتييى داشت.
فنوتييى مثبت معنىدارى نشان داد كه با نتايج كوناته و همكاران (Konate et al., 2016) مطابقت داشت. درصد بارورى همبستخى مثبت فنوتييى معنى دار با تعداد دانه ير

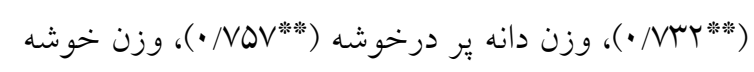

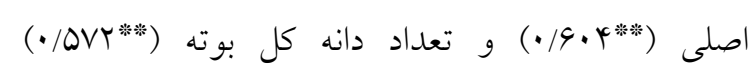
داشت. عملكرد بيولوزيك نيز با تعداد خوشه، وزن هزاردانه، تعداد كل دانه در خوشه همبستكى مثبت داشت بئت كه با نتايج هنرنزاد (Honarnejad, 2002)، مهدوى و و همكاران (Mahdavi et al., 2003) و كوهرى و همكاران (Gohari et al., 2010)

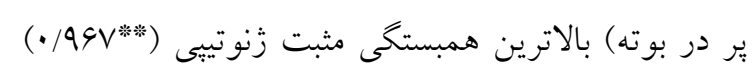

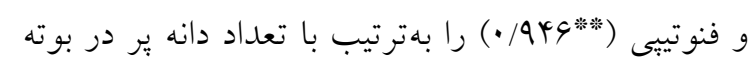

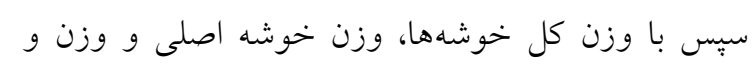
تعداد دانه ير در خوشه و تعداد خوشه پهه ثانويه داشت. فنتاى و همكاران (Fentie et al., 2014) درآزمايشى بر روى rا زنوتيٍّ برنج همبستكى مثبت و معنى دار فنوتييى

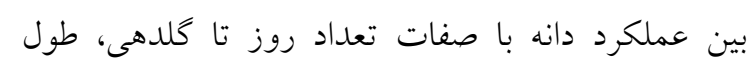

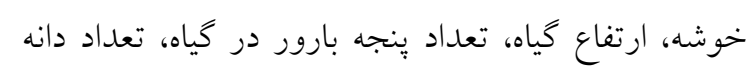
در خوشه و تعداد دانه ير در خوشه را گزارش كردند. زيستتوده نيز بالاترين همبستكى هاى مثبت را با عملكرد

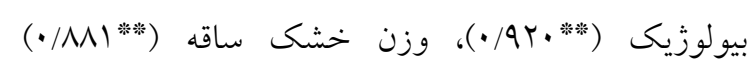

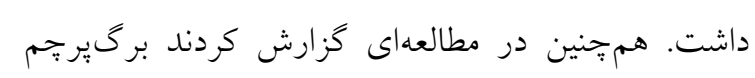

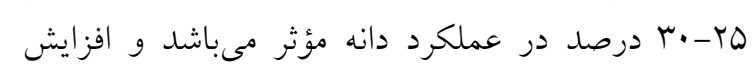

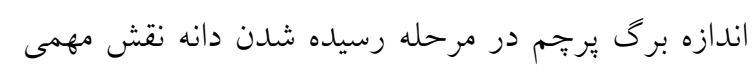
در جذب بيشتر نور و افزايش ميزان فتوسنتز و افزايش عملكرد دانه گندم مىتواند داشته باشد ( Mahmood and Cowdhry, 2000 . ونكاتا لاكشمى و و همكاران ميان عملكرد دانه با (Venkata-Lakshmi et al., 2014) صفات تعداد روز تا رسيدگى، ارتفاع بوته، تعداد بِنجه بارور در كياه همبستخى مثبت فنوتييى و زنوتييى معنىدار

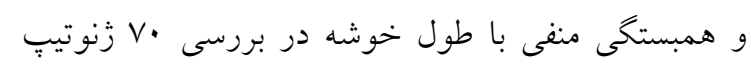

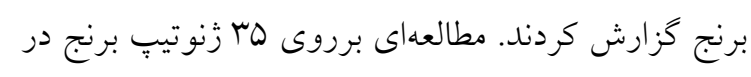

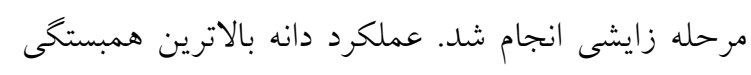
فنوتييى و زنوتييى را با تعداد ريشه، روز تا •ها له درصد

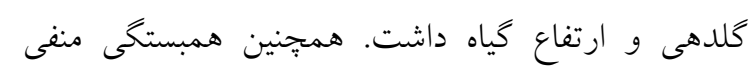




$$
\text { جدول r- ضرايب همبستكى فنوتييى (بالاى قطر) و زنوتييى (يايين قطر) بين صفات تحت شرايط بدون تنش }
$$

Table 3. Phenotypic (above diagonal) and genotypic (blow diagonal) correlation coefficients among studied traits under normal (non-stress) condition

\begin{tabular}{|c|c|c|c|c|c|c|c|c|c|c|c|c|}
\hline $\begin{array}{l}\text { فات } \\
\text { Trai }\end{array}$ & BY & PH & & TNP & FLA & MPL & $\mathrm{H}$ & DF & DM & DP & SD & $\mathrm{TH}$ \\
\hline BY & 1 & 414 & $0.428^{\circ}$ & $0.521^{*}$ & $0.145^{\mathrm{ns}}$ & $0.261^{\mathrm{ns}}$ & 0.28 & 0.28 & $-0.023^{\mathrm{ns}}$ & -0.04 & $-0.01^{\mathrm{ns}}$ & $0.5^{\mathrm{ns}}$ \\
\hline PH & 0.405 & 1 & $-0.126^{\mathrm{ns}}$ & $0.307^{\mathrm{ns}}$ & $0.527^{*}$ & $0.502^{\mathrm{ns}}$ & $0.078^{\mathrm{ns}}$ & $0.082^{\mathrm{ns}}$ & $0.082^{\mathrm{ns}}$ & -0.05 & $0.413^{\mathrm{ns}}$ & $0.196^{\mathrm{ns}}$ \\
\hline PNP & & $-0.170^{\mathrm{ns}}$ & 1 & $0.714^{*}$ & $-0.219^{\mathrm{ns}}$ & $-0.141^{\mathrm{ns}}$ & $-0.079^{\mathrm{ns}}$ & $-0.244^{\mathrm{ns}}$ & $-0.27^{\mathrm{ns}}$ & & -0.21 & $.066^{\mathrm{ns}}$ \\
\hline TNP & 0 & $-0.121^{\mathrm{ns}}$ & .678 & 1 & -0.126 & $-0.046^{\mathrm{ns}}$ & -0.125 & $-0.238^{n s}$ & $-0.241^{\mathrm{ns}}$ & 0.19 & $-0.018^{\mathrm{ns}}$ & $.155^{\mathrm{ns}}$ \\
\hline FLA & & $0.280^{*}$ & & $0.155^{\mathrm{ns}}$ & 1 & $0.387^{*}$ & $0.096^{\mathrm{ns}}$ & $0.04^{\mathrm{ns}}$ & $0.058^{\mathrm{ns}}$ & $-0.012^{n s}$ & $-0.005^{\mathrm{ns}}$ & $0.267^{\mathrm{ns}}$ \\
\hline MPL & & $0.502^{* *}$ & $-0.137^{\mathrm{ns}}$ & $0.040^{\mathrm{ns}}$ & $0.368^{* *}$ & 1 & $0.0242^{\mathrm{ns}}$ & $0.0238^{\mathrm{ns}}$ & $0.055^{\mathrm{ns}}$ & & $0.244^{\mathrm{ns}}$ & $0.279^{\mathrm{ns}}$ \\
\hline PELSH & & & $-0.070^{\mathrm{ns}}$ & $-0.121^{\mathrm{ns}}$ & $0.094^{\mathrm{ns}}$ & $0.232^{* *}$ & 1 & $0.149^{\mathrm{ns}}$ & $0.156^{\mathrm{ns}}$ & -0.1 & $-0.061^{\mathrm{ns}}$ & $0.510^{*}$ \\
\hline DF & 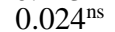 & $6^{\mathrm{ns}}$ & $1^{*}$ & $-0.227^{* *}$ & $9^{\text {ns }}$ & $0.023^{\mathrm{ns}}$ & $0.148^{\mathrm{ns}}$ & 1 & $0.963^{*}$ & $-0.916^{*}$ & $-0.012^{\mathrm{ns}}$ & $0.017^{\mathrm{ns}}$ \\
\hline DM & & & & $-0.229^{*}$ & $0.058^{\text {ns }}$ & $0.056^{\mathrm{ns}}$ & $0.156^{\mathrm{ns}}$ & $0.961^{* *}$ & 1 & $-0.776^{\mathrm{ns}}$ & $-0.034^{\mathrm{ns}}$ & $0.05^{\mathrm{ns}}$ \\
\hline DP & & -0. & & $-0.190^{*}$ & $-0.011^{\mathrm{ns}}$ & $2^{\text {ns }}$ & $-0.106^{\mathrm{ns}}$ & $-0.911^{* *}$ & $-0.762^{* * *}$ & 1 & $-0.017^{\mathrm{ns}}$ & $.031^{\mathrm{ns}}$ \\
\hline SD & & $1^{* * *}$ & -0.1 & $0.018^{\mathrm{ns}}$ & $0.0249^{* *}$ & $0.220^{*}$ & $-0.058^{\mathrm{ns}}$ & $0.011^{\mathrm{ns}}$ & $-0.033^{\mathrm{ns}}$ & -0.01 & 1 & $.253^{\mathrm{ns}}$ \\
\hline TPW & & & $.079^{n s}$ & 0.136 & $0.227^{\mathrm{ns}}$ & $0.237^{\mathrm{ns}}$ & $0.560^{*}$ & $4^{\mathrm{ns}}$ & $\mathrm{ns}$ & & $0.208^{\mathrm{ns}}$ & 1 \\
\hline MPW & & & & $38^{*}$ & $0.936^{* *}$ & $24^{\mathrm{ns}}$ & $0.374^{* *}$ & $73^{\mathrm{ns}}$ & & & $-0.018^{\mathrm{ns}}$ & $0.920^{* *}$ \\
\hline NFG & $0.339^{* *}$ & & $8^{* *}$ & $0.268^{* *}$ & $0.403^{\text {** }}$ & $0.234^{*}$ & $0.219^{*}$ & & $9^{\mathrm{ns}}$ & 0.2 & & $0.409^{* *}$ \\
\hline NPB & $-0.3^{* *}$ & & $-0.259^{* *}$ & $-0.148^{\mathrm{ns}}$ & $0.441^{* *}$ & $-0.339^{*}$ & $-0.137^{\mathrm{ns}}$ & $-0.092^{\mathrm{ns}}$ & & & 0 . & $.367^{* *}$ \\
\hline NSB & & & & $0.051^{\mathrm{ns}}$ & $0.514^{* *}$ & $-0.265^{*}$ & $15^{* *}$ & $-0.027^{\mathrm{ns}}$ & $3^{\text {ns }}$ & -0 . & $51^{* * *}$ & $0.509^{* *}$ \\
\hline SDW & & & & & & & & $4^{\text {ns }}$ & $8^{\mathrm{ns}}$ & & & $0.198^{*}$ \\
\hline FGWP & & & & & & & & $4^{\mathrm{ns}}$ & & & & $.291^{* * *}$ \\
\hline TGNP & & & & & & & & $54^{\mathrm{ns}}$ & & & & $144^{\mathrm{ns}}$ \\
\hline FGWP & & & & & & & & & & & & $19^{\text {ns }}$ \\
\hline $\mathrm{GW}$ & & & & & & & & & & & & $08^{\text {ns }}$ \\
\hline $0 \mathrm{GW}$ & & & & & & & & & & & & $55^{\mathrm{ns}}$ \\
\hline FP & & & & & & & & & & & & \\
\hline B & $0.673^{*}$ & $601^{*}$ & 287 & $0.524^{*}$ & 0.232 & $0.609^{*}$ & $0.824^{*}$ & $0.831^{*}$ & $0.248^{\mathrm{ns}}$ & 0.251 & 0.354 & $0.508^{*}$ \\
\hline
\end{tabular}

$$
\text { ادامه جدول roh }
$$

\begin{tabular}{|c|c|c|c|c|c|c|c|c|c|c|c|c|}
\hline $\begin{array}{l}\text { صفات } \\
\text { Traits }\end{array}$ & MPW & $\mathrm{NFG}$ & NPB & NSB & SDW & FGWP & TGNP & FGWP & $100 \mathrm{GW}$ & $1000 \mathrm{GW}$ & FP & B \\
\hline BY & $0.252^{\mathrm{ns}}$ & $0.11^{\mathrm{ns}}$ & $0.219^{\mathrm{ns}}$ & $0.247^{\mathrm{ns}}$ & $0.94^{\mathrm{ns}}$ & $0.124^{\mathrm{ns}}$ & $0.377^{*}$ & $0.390^{*}$ & $0.229^{\mathrm{ns}}$ & $0.23^{\mathrm{ns}}$ & $-0.018^{\mathrm{ns}}$ & $0.923^{*}$ \\
\hline PH & $0.337^{\mathrm{ns}}$ & $0.219^{\mathrm{ns}}$ & $0.341^{\mathrm{ns}}$ & $0.277^{\mathrm{ns}}$ & $0.41^{\mathrm{ns}}$ & $0.24^{\mathrm{ns}}$ & $0.222^{\mathrm{ns}}$ & $0.246^{\mathrm{ns}}$ & $0.221^{\mathrm{ns}}$ & $0.223^{\text {ns }}$ & $0.201^{\mathrm{ns}}$ & $0.415^{\mathrm{ns}}$ \\
\hline PNP & $-0.31^{\mathrm{ns}}$ & $-0.370^{*}$ & $-0.276^{\mathrm{ns}}$ & $-0.157 \mathrm{~ns}$ & $0.461^{\mathrm{ns}}$ & $-0.356^{\mathrm{ns}}$ & $-0.111^{\mathrm{ns}}$ & $-0.114^{\mathrm{ns}}$ & $-0.114^{\mathrm{ns}}$ & $0.077^{\mathrm{ns}}$ & $-0.322^{\mathrm{ns}}$ & $0.383^{\mathrm{ns}}$ \\
\hline TNP & $-0.186^{\mathrm{ns}}$ & $-0.276^{\mathrm{ns}}$ & $-0.098^{\mathrm{ns}}$ & $-0.057^{\mathrm{ns}}$ & $0.532^{\mathrm{ns}}$ & $-0.28^{n s}$ & $-0.021 \mathrm{~ns}$ & $-0.031^{\mathrm{ns}}$ & $-0.041^{\mathrm{ns}}$ & $-0.043^{\mathrm{ns}}$ & $-0.262^{\mathrm{ns}}$ & $0.525^{*}$ \\
\hline FLA & $0.293^{\mathrm{ns}}$ & $0.3^{\mathrm{ns}}$ & $0.37^{\mathrm{ns}}$ & $0.471^{\mathrm{ns}}$ & $0.098^{\mathrm{ns}}$ & $0.345^{\mathrm{ns}}$ & $0.245^{\mathrm{ns}}$ & $0.257^{\mathrm{ns}}$ & $0.216^{\mathrm{ns}}$ & $0.221^{\mathrm{ns}}$ & $0.056^{\mathrm{ns}}$ & $0.213^{\mathrm{ns}}$ \\
\hline MPL & $0.390^{*}$ & $0.356^{*}$ & $0.454^{*}$ & $0.504^{\mathrm{ns}}$ & $0.25^{\mathrm{ns}}$ & $0.384^{\mathrm{ns}}$ & $0.236^{\mathrm{ns}}$ & $0.281^{\mathrm{ns}}$ & $0.281^{\mathrm{ns}}$ & $0.285^{\mathrm{ns}}$ & $0.059^{\mathrm{ns} n \mathrm{~ns}}$ & $0.308^{\mathrm{ns}}$ \\
\hline PELSH & $0.082^{\mathrm{ns}}$ & $0.144^{\mathrm{ns}}$ & $0.184^{\mathrm{ns}}$ & $0.064^{\mathrm{ns}}$ & $0.226^{\mathrm{ns}}$ & $0.127^{\mathrm{ns}}$ & $0.073^{\mathrm{ns}}$ & $0.054^{\mathrm{ns}}$ & $0.01^{\mathrm{ns}}$ & $0.008^{\mathrm{ns}}$ & $0.164^{\mathrm{ns}}$ & $0.145^{\mathrm{ns}}$ \\
\hline DF & $0.155^{\mathrm{ns}}$ & $0.257^{\mathrm{ns}}$ & $0.169^{\mathrm{ns}}$ & $0.057^{\mathrm{ns}}$ & $-0.036^{\mathrm{ns}}$ & $0.247^{\mathrm{ns}}$ & $0.073^{\mathrm{ns}}$ & $0.061^{\mathrm{ns}}$ & $-0.024^{\mathrm{ns}}$ & $-0.024^{\mathrm{ns}}$ & $0.183^{\mathrm{ns}}$ & $0.019^{\mathrm{ns}}$ \\
\hline DM & $0.177^{\mathrm{ns}}$ & $0.277^{\mathrm{ns}}$ & $0.172^{\mathrm{ns}}$ & $0.0759^{\mathrm{ns}}$ & $-0.078^{\mathrm{ns}}$ & $0.278^{\mathrm{ns}}$ & $0.088^{\mathrm{ns}}$ & $0.093^{\mathrm{ns}}$ & $-0.001^{\mathrm{ns}}$ & $-0.002^{\mathrm{ns}}$ & $0.207^{\mathrm{ns}}$ & $-0.008^{n s}$ \\
\hline DP & $-0.1^{\mathrm{ns}}$ & $-0.189^{\mathrm{ns}}$ & $-0.141^{\mathrm{ns}}$ & $-0.024^{\mathrm{ns}}$ & $-0.027^{n s}$ & $-0.166^{\mathrm{ns}}$ & $-0.04^{\mathrm{ns}}$ & $-0.007^{\mathrm{ns}}$ & $0.05^{\mathrm{ns}}$ & $0.047^{\mathrm{ns}}$ & $-0.116^{\mathrm{ns}}$ & $-0.057^{\mathrm{ns}}$ \\
\hline SD & $0.238^{\mathrm{ns}}$ & $0.142^{\mathrm{ns}}$ & $0.359^{\mathrm{ns}}$ & $0.312^{\mathrm{ns}}$ & $0.236^{\mathrm{ns}}$ & $0.146^{\mathrm{ns}}$ & $0.267^{\mathrm{ns}}$ & $0.254^{\mathrm{ns}}$ & $0.121^{\mathrm{ns}}$ & $0.127^{\mathrm{ns}}$ & $0.018^{\mathrm{ns}}$ & $0.348^{\mathrm{ns}}$ \\
\hline TPW & $0.721^{*}$ & $0.635^{*}$ & $0.354^{\mathrm{ns}}$ & $0.600^{*}$ & $0.234^{\mathrm{ns}}$ & $0.648^{*}$ & $0.858^{*}$ & $0.863^{*}$ & $59^{n s}$ & $0.262^{\mathrm{ns}}$ & $0.373^{*}$ & $0.505^{*}$ \\
\hline MPW & 1 & $0.86^{\mathrm{ns}}$ & $0.49^{\text {ns }}$ & $3^{*}$ & $03^{\mathrm{ns}}$ & $48^{*}$ & $40^{*}$ & $38^{*}$ & $04^{\mathrm{ns}}$ & $0.21^{\mathrm{ns}}$ & $0.611^{*}$ & $0.262^{\mathrm{ns}}$ \\
\hline NFG & $0.874^{* *}$ & 1 & $0.461^{\mathrm{ns}}$ & $0.595^{\mathrm{ns}}$ & $-0.11^{\mathrm{ns}}$ & $0.960^{* *}$ & $0.733^{*}$ & $0.700^{*}$ & $0.041^{\mathrm{ns}}$ & $0.046^{\mathrm{ns}}$ & $0.733^{*}$ & $0.109^{\mathrm{ns}}$ \\
\hline NPB & $0.466^{* *}$ & $0.428^{* *}$ & $\begin{array}{c}.401 \\
1\end{array}$ & $0.459^{*}$ & $0.087^{\mathrm{ns}}$ & $0.428^{*}$ & $0.0048^{\mathrm{ns}}$ & 0.2036 & $1.158^{* * *}$ & $0.1156^{\mathrm{ns}}$ & $0.0166^{\mathrm{ns}}$ & $0.909^{* *}$ \\
\hline NSB & $2^{* * *}$ & $0.574^{* *}$ & $0.420^{* *}$ & 1 & $081^{\text {ns }}$ & $0.549^{n s}$ & $33^{\mathrm{ns}}$ & $0.510^{*}$ & $0.089^{\mathrm{ns}}$ & $93^{n s}$ & $0.185^{\mathrm{ns}}$ & $0.289^{\mathrm{ns}}$ \\
\hline SDW & $-0.026^{\mathrm{ns}}$ & $0.226^{*}$ & $0.032^{\text {ns }}$ & $-0.107^{\mathrm{ns}}$ & 1 & $-0.093^{n s}$ & $0.115^{\mathrm{ns}}$ & $0.123^{n s}$ & $0.161^{\mathrm{ns}}$ & $0.162^{\mathrm{ns}}$ & $-0.186^{\mathrm{ns}}$ & $0.880^{*}$ \\
\hline FGWP & $0.879^{* *}$ & $0.956^{* *}$ & 0.4 & $0.527^{*}$ & $-0.091^{\mathrm{ns}}$ & 1 & $0.722^{*}$ & $0.734^{*}$ & $0.208^{\mathrm{ns}}$ & $0.214^{\mathrm{ns}}$ & $0.732^{*}$ & $0.124^{\mathrm{ns}}$ \\
\hline TGNP & $0.719^{* *}$ & $0.727^{* *}$ & $0.383^{* *}$ & $0.513^{* *}$ & $0.116^{\mathrm{ns}}$ & $0.717^{* *}$ & 1 & $0.967^{* *}$ & $0.152^{\mathrm{ns}}$ & $0.156^{\mathrm{ns}}$ & $0.575^{*}$ & $0.391^{\mathrm{ns}}$ \\
\hline FGWP & $0.699^{*}$ & $0.676^{*}$ & $0.203^{\mathrm{ns}}$ & $0.44^{\mathrm{ns}}$ & $0.118^{\mathrm{ns}}$ & $0.708^{*}$ & $0.964^{* * *}$ & 1 & $0.308^{*}$ & $0.313^{\mathrm{ns}}$ & $0.555^{*}$ & $0.390^{*}$ \\
\hline $100 \mathrm{GW}$ & $0.189^{\mathrm{ns}}$ & $0.037^{\mathrm{ns}}$ & $1.15^{\text {** }}$ & $0.076^{\mathrm{ns}}$ & $0.154^{\mathrm{ns}}$ & $0.197^{\mathrm{ns}}$ & $0.149^{\mathrm{ns}}$ & $0.304^{*}$ & 1 & $0.999^{* *}$ & $0.053^{\mathrm{ns}}$ & $0.242^{\mathrm{ns}}$ \\
\hline $1000 \mathrm{GW}$ & $0.211^{*}$ & $0.047^{\mathrm{ns}}$ & $0.076^{\mathrm{ns}}$ & $0.090^{\text {ns }}$ & $0.161^{\mathrm{ns}}$ & $0.213^{* *}$ & $0.158^{\text {ns }}$ & $0.309^{*}$ & $0.998^{\mathrm{ns}}$ & 1 & $0.0569^{\mathrm{ns}}$ & $0.245^{\mathrm{ns}}$ \\
\hline FP & $0.604^{* * *}$ & $0.732^{* * *}$ & $0.091^{\mathrm{ns}}$ & $0.178^{\mathrm{ns}}$ & $-0.184^{*}$ & $0.727^{* * *}$ & $0.572^{* * *}$ & $0.543^{*}$ & $0.052^{\mathrm{ns}}$ & $0.057^{\mathrm{ns}}$ & 0 & $-0.059 \mathrm{~ns}$ \\
\hline B & $0.258^{* * *}$ & $0.109^{\text {ns }}$ & $0.200^{*}$ & $0.279^{\text {** }}$ & $0.881^{* *}$ & $0.123^{\text {ns }}$ & $0.389^{\text {** }}$ & $0.379^{\mathrm{ns}}$ & $0.234^{\mathrm{ns}}$ & $0.243^{\text {*** }}$ & $-0.059^{\mathrm{ns}}$ & 1 \\
\hline
\end{tabular}

Continued from Table 3

ns, * and **: Non-significant, significant at $5 \%$ and $1 \%$ probability level, respectively

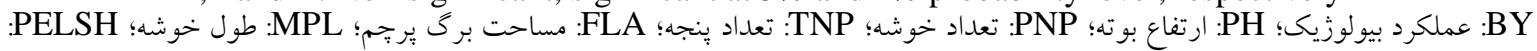

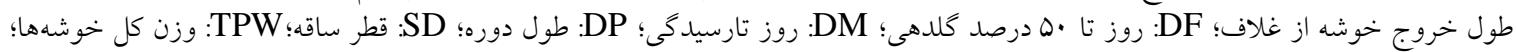

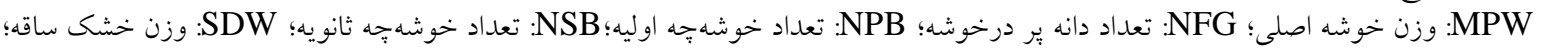

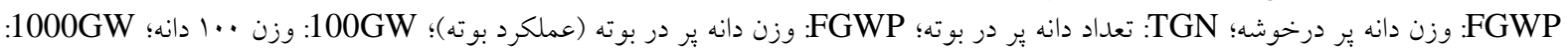

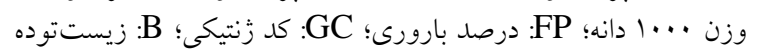

BY: Biological yield; PH: Plant height; PNP: Panicle number in plant; TNP: Tiller number in plant; FLA: Flag leaf area; MPL: The main panicle length; PELSH: The panicle exit length from sheath; DF: Days to $50 \%$

flowering; DM: Daye's to maturity; DP: During the period; SD: Stem diameter; TPW: Total panicle weight;

MPW: The main panicle weight; NFG: Number of filled grain in panicle; NPB: Number of primary branches;

NSB: Number of Secondary branches; SDW: Stem dry weight; FGWP: Filled grain weight in panicle; TGN:

Total grain number in plant; FGWP: Filled grain weight in plant (grain yield); 100GW: 100 grain weight; 1000GW: 1000 grain weight; FP: Fertility percent; GC: Genotypic code; B: Biomass 


$$
\text { جدول \& - همبستخى فنوتييى (بالاى قطر) و زنوتييى (بايين قطر) صفات براى شرايط تنش شورى }
$$

Table 4. Phenotypic (above diagonal) and genotypic (blow diagonal) correlation coefficients among studied traits under salinity stress condition

\begin{tabular}{|c|c|c|c|c|c|c|c|c|c|c|c|c|c|}
\hline ت & B & $\mathrm{P}$ & PNP & TNP & FLA & MPL & PELSH & 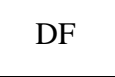 & DM & L & $\mathrm{S}$ & TPW & MPW \\
\hline BY & 1 & .571 & $0.49^{\mathrm{ns}}$ & $467^{\mathrm{ns}}$ & $0.233^{\mathrm{n}}$ & $.336^{\circ}$ & $12^{n}$ & 085 & 0.07 & -0.133 & $0.384^{*}$ & $0.683^{*}$ & .478 \\
\hline $\mathrm{PH}$ & $554^{* *}$ & 1 & $268^{\mathrm{ns}}$ & $072^{\mathrm{ns}}$ & $49^{\mathrm{ns}}$ & $57^{\mathrm{ns}}$ & $61^{\mathrm{ns}}$ & 0.090 & 0.070 & 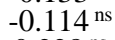 & $092^{\mathrm{ns}}$ & $0.374^{*}$ & 8 \\
\hline PNP & $9 *$ & $251^{* *}$ & 1 & $.583^{*}$ & $085^{\mathrm{ns}}$ & $4^{\mathrm{ns}}$ & $62^{\mathrm{ns}}$ & $-0.432^{*}$ & $-0.349^{*}$ & & 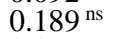 & $0.457^{*}$ & \\
\hline TNP & & $077^{\mathrm{ns}}$ & $0.566^{* *}$ & 20 & $006^{\mathrm{ns}}$ & & ns & $-0.272^{\mathrm{ns}}$ & $36^{\mathrm{ns}}$ & 0 . & 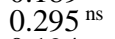 & & 1 \\
\hline FLA & & & & $014^{\mathrm{ns}}$ & 1 & $546^{*}$ & & $0.063^{\mathrm{ns}}$ & & & 94 & $0.2+3$ & $04^{* *}$ \\
\hline MPL & & & $4^{* *}$ & & $0.494^{* * *}$ & & - 12 & & & -( & ns & $5 *$ & \\
\hline PELSH & & & & & & 2 & & & & & & & \\
\hline DF & & & & & & & & 1 & & & & 0.0 & \\
\hline DM & & 0.0 & $2^{* *}$ & & & & & & 1 & $-0.914^{*}$ & & 0.0 & \\
\hline DP & & & & & & & & & & 1 & $-0.027^{\mathrm{ns}}$ & -0.1 & \\
\hline SD & & & $2^{\mathrm{ns}}$ & $1^{* * *}$ & & & & & $6^{* *}$ & -0.01 & 1 & $0.366^{*}$ & \\
\hline TPW & & & $09^{*}$ & $9^{\text {ns }}$ & ns & & & & $1^{\mathrm{ns}}$ & -0. & $0.304^{\mathrm{ns}}$ & 1 & $0.737^{*}$ \\
\hline MPW & & & $5^{\mathrm{ns}}$ & -0.0 & & & & & ns & -0.2 & $0.265^{\mathrm{ns}}$ & $0.798^{\mathrm{ns}}$ & 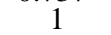 \\
\hline NFG & $7^{*}$ & & $5^{\mathrm{ns}}$ & $-0.008^{n s}$ & $5^{*}$ & & $73^{*}$ & & & $5^{\mathrm{ns}}$ & $0.204^{\mathrm{ns}}$ & $0.717^{*}$ & $37^{*}$ \\
\hline NPB & $2^{\mathrm{ns}}$ & & $2^{\mathrm{ns}}$ & $-0.009^{n s}$ & $0.302^{*}$ & 0. & 0 . & & & -0 & $0.367^{*}$ & $4^{*}$ & $2^{* *}$ \\
\hline NSB & $1 \mathrm{~ns}$ & $0.326^{*}$ & $0.22^{\mathrm{ns}}$ & $0.098^{\mathrm{ns}}$ & $0.377^{*}$ & 0. & $7 \mathrm{~ns}$ & ns & & -0 & $0.305^{*}$ & $8^{*}$ & $1^{\text {** }}$ \\
\hline SDW & & $0.566^{*}$ & & $0.466^{*}$ & $0.218^{\mathrm{ns}}$ & 0.3 & & & & $25^{\mathrm{ns}}$ & $0.364^{*}$ & $0.594^{*}$ & $9^{* *}$ \\
\hline FGWP & & $9^{*}$ & $0.075^{\mathrm{ns}}$ & $0.019^{\mathrm{ns}}$ & $5^{\mathrm{ns}}$ & & & & & $-0.241^{\mathrm{ns}}$ & $0.204^{\mathrm{ns}}$ & $0.761^{*}$ & $67^{\text {** }}$ \\
\hline TGNP & & & & & $3^{\mathrm{ns}}$ & 0. & & & $7^{\mathrm{ns}}$ & $-0.177^{\mathrm{ns}}$ & $0.256^{\mathrm{ns}}$ & $0.848^{*}$ & $0^{* * *}$ \\
\hline FGWP & $5^{*}$ & $0.368^{*}$ & $9^{\mathrm{ns}}$ & & $4^{\mathrm{ns}}$ & & & & & $76^{\mathrm{ns}}$ & $0.254^{\mathrm{ns}}$ & $0.851^{*}$ & $0.750^{*}$ \\
\hline 100GW & $6^{\mathrm{ns}}$ & $0.281^{\mathrm{ns}}$ & $0.27^{\mathrm{ns}}$ & $6^{\mathrm{ns}}$ & $0.264^{\mathrm{ns}}$ & & $6^{\mathrm{ns}}$ & $4^{\mathrm{ns}}$ & $-0.001^{\mathrm{ns}}$ & & $0.155^{\mathrm{ns}}$ & & 0.325 \\
\hline $1000 \mathrm{GW}$ & $8^{\mathrm{ns}}$ & & $0.272^{\mathrm{ns}}$ & & $0.266^{\mathrm{ns}}$ & & & & $01^{\mathrm{ns}}$ & & & & \\
\hline FP & 241 & $2^{n s}$ & $0.016^{\mathrm{ns}}$ & $9^{\mathrm{ns}}$ & $0.147^{\mathrm{ns}}$ & $\mathrm{ns}$ & & & $1^{\mathrm{ns}}$ & -0.2 & $3^{\mathrm{ns}}$ & $0.516^{*}$ & $19^{* *}$ \\
\hline GC & $-0.282^{\mathrm{ns}}$ & $2^{*}$ & $-0.22^{\mathrm{ns}}$ & & $-0.276^{\mathrm{ns}}$ & -0.1 & $-0.26^{\mathrm{ns}}$ & $-0.126^{\mathrm{ns}}$ & $-0.056^{\mathrm{ns}}$ & -0.0 & $-0.128^{n s}$ & $-0.345^{*}$ & $-0.335^{\mathrm{ns}}$ \\
\hline 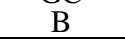 & $0.953^{* *}$ & $78^{*}$ & $0.520^{*}$ & & $0.227^{\mathrm{ns}}$ & 0.3 & -0.2 & $0.066^{\mathrm{ns}}$ & $2^{\mathrm{ns}}$ & -0. & $0.356^{*}$ & $0.688^{*}$ & $0.469^{* *}$ \\
\hline
\end{tabular}

ادامه جدول

Continued from Table 4

\begin{tabular}{|c|c|c|c|c|c|c|c|c|c|c|c|c|}
\hline Trai & NFG & NPB & NSB & SDW & $\mathrm{FG}$ & TGNP & FG & 100 & 100 & FP & GC & B \\
\hline BY & $0.413^{*}$ & $0.178^{\mathrm{ns}}$ & $0.449^{*}$ & $0.987^{*}$ & $0.437^{\prime \prime}$ & $0.541^{\prime \prime}$ & $0.527^{*}$ & $0.189^{\mathrm{ns}}$ & $0.196^{*}$ & $0.236^{6 \cdots}$ & $-0.274^{3 *}$ & 0.954 \\
\hline PH & $0.315^{\text {** }}$ & $0.170^{\mathrm{ns}}$ & $0.316^{* *}$ & $0.546^{* *}$ & $0.334^{* *}$ & $0.346^{* *}$ & $0.328^{*}$ & $0.249^{\mathrm{ns}}$ & $0.276^{* *}$ & $0.199^{\mathrm{ns}}$ & $-0.334^{* *}$ & $0.561^{* *}$ \\
\hline PNP & $0.061^{\mathrm{ns}}$ & $0.154^{\mathrm{ns}}$ & $0.210^{*}$ & $0.445^{* *}$ & $0.077^{\mathrm{ns}}$ & $0.182^{\mathrm{ns}}$ & $0.17^{\mathrm{ns}}$ & $0.226^{\mathrm{ns}}$ & $0.262^{* *}$ & $0.022^{\mathrm{ns}}$ & -0.21 & $0.505^{\text {** }}$ \\
\hline TNP & $-0.009^{n s}$ & $0.005^{\mathrm{ns}}$ & $2^{\text {ns }}$ & $0.445^{\text {** }}$ & $0.028^{\mathrm{ns}}$ & $0.119^{\mathrm{ns}}$ & $0.095^{\mathrm{ns}}$ & $0.042^{\mathrm{ns}}$ & $0.052^{\mathrm{ns}}$ & $-0.061^{\mathrm{ns}}$ & -0.03 & $0.035^{\mathrm{ns}}$ \\
\hline FLA & $0.301^{* *}$ & $0.285^{* *}$ & $0.348^{* * *}$ & $0.201^{*}$ & $0.262^{* *}$ & $0.270^{* *}$ & $0.174^{\mathrm{ns}}$ & $0.202^{*}$ & $0.246^{* *}$ & $0.138^{\mathrm{ns}}$ & $-0.256^{* * *}$ & $0.210^{*}$ \\
\hline MPL & $0.385^{* *}$ & $0.621^{* *}$ & $0.559^{* *}$ & $0.285^{* *}$ & $0.387^{* * *}$ & $0.352^{* *}$ & $0.288^{\text {ns }}$ & $0.253^{*}$ & $0.292^{* *}$ & $0.199^{\text {ns }}$ & $0.199^{\text {ns }}$ & $0.199^{\text {ns }}$ \\
\hline PELSH & 0 & $0.165^{\mathrm{ns}}$ & $0.163^{\mathrm{ns}}$ & $0.271^{\text {** }}$ & $0.479^{* *}$ & $0.354^{* *}$ & $0.359^{*}$ & $0.159^{\mathrm{ns}}$ & $0.146^{\mathrm{ns}}$ & $0.414^{\text {** }}$ & $-0.253^{\mathrm{ns}}$ & $0.272^{* *}$ \\
\hline $\mathrm{DF}$ & $0.237^{* *}$ & $0.141^{\mathrm{ns}}$ & $0.200^{*}$ & $0.087^{\mathrm{ns}}$ & $0.223^{*}$ & $0.131^{\mathrm{ns}}$ & $0.135^{\mathrm{ns}}$ & $-0.024^{\mathrm{ns}}$ & $-0.024^{\mathrm{ns}}$ & $0.191^{*}$ & $-0.122^{\mathrm{ns}}$ & $0.066^{\mathrm{ns}}$ \\
\hline DM & $0.234^{*}$ & $0.156^{\mathrm{ns}}$ & $0.194^{* *}$ & 0.079 & $0.225^{*}$ & $0.148^{\mathrm{ns}}$ & $0.132^{\mathrm{ns}}$ & $0.0008^{\mathrm{ns}}$ & $0.000^{\mathrm{ns}}$ & $0.197^{*}$ & $-0.049^{n s}$ & $0.068^{\mathrm{ns}}$ \\
\hline DP & $-0.201^{*}$ & $-0.132^{\mathrm{ns}}$ & $-0.162^{\mathrm{ns}}$ & $-0.101^{\mathrm{ns}}$ & $-0.192^{*}$ & $-0.143^{\mathrm{ns}}$ & $-0.099^{n s}$ & $0.007^{\mathrm{ns}}$ & $0.013^{\mathrm{ns}}$ & $-0.175^{\mathrm{ns}}$ & $-0.032^{\mathrm{ns}}$ & $-0.095^{\mathrm{ns}}$ \\
\hline SD & $0.194^{*}$ & $0.357^{\text {** }}$ & $0.288^{* *}$ & $0.342^{* *}$ & $0.204^{*}$ & $0.243^{* *}$ & 0.213 & $0.125^{\mathrm{ns}}$ & $0.141^{\mathrm{ns}}$ & $0.040^{\mathrm{ns}}$ & $-0.118^{\mathrm{ns}}$ & $0.339^{* *}$ \\
\hline TPW & $0.654^{*}$ & $0.370^{*}$ & $0.531^{*}$ & $0.539^{*}$ & $0.690^{*}$ & $0.778^{*}$ & $0.781^{*}$ & $0.367^{*}$ & 0.367 & $0.464^{\mathrm{ns}}$ & $-0.279^{n s}$ & $0.652^{*}$ \\
\hline MPW & $0.789^{*}$ & $0.499^{*}$ & $0.639^{*}$ & $0.419^{*}$ & $0.884^{*}$ & $0.814^{*}$ & $0.821^{*}$ & $0.360^{*}$ & $0.358^{*}$ & $0.657^{*}$ & $-0.361^{*}$ & $0.485^{*}$ \\
\hline NFG & 1 & $0.423^{*}$ & $0.546^{*}$ & $0.341^{*}$ & $0.966^{* *}$ & $0.890^{*}$ & $0.858^{*}$ & $0.286^{*}$ & $0.285^{\mathrm{ns}}$ & $0.847^{*}$ & $-0.304^{\mathrm{ns}}$ & $0.406^{*}$ \\
\hline NPB & $0.405^{* * *}$ & 1 & $0.546^{* *}$ & $0.125^{\mathrm{ns}}$ & $0.365^{* *}$ & $0.335^{* *}$ & 48 & $0.976^{* *}$ & $0.294^{* *}$ & $0.258^{* *}$ & $-0.227^{*}$ & $0.183^{\mathrm{ns}}$ \\
\hline NSB & $0.530^{* *}$ & $0.546^{* *}$ & 1 & $0.409^{*}$ & $0.489^{*}$ & $0.504^{*}$ & $0.431^{*}$ & $79^{\mathrm{ns}}$ & $79^{\mathrm{ns}}$ & $0.212^{\mathrm{ns}}$ & $-0.287^{\mathrm{ns}}$ & $0.449^{*}$ \\
\hline SDW & $0.337^{\text {** }}$ & $0.125^{\mathrm{ns}}$ & $0.394^{* *}$ & 1 & $0.364^{*}$ & $0.461^{*}$ & $0.459^{*}$ & $0.142^{\mathrm{ns}}$ & $0.144^{\mathrm{ns}}$ & $0.175^{\mathrm{ns}}$ & $-0.264^{\mathrm{ns}}$ & $0.935^{*}$ \\
\hline FGWP & $0.958^{* *}$ & $0.365^{\text {** }}$ & $0.479^{* *}$ & $0.352^{* *}$ & 1 & $0.891^{*}$ & $0.899^{*}$ & $0.330^{*}$ & $0.328^{*}$ & $0.844^{*}$ & $-0.309^{\mathrm{ns}}$ & $0.436^{*}$ \\
\hline TGNP & $0.887^{* *}$ & $0.335^{* *}$ & $0.492^{* *}$ & $0.456^{* *}$ & $0.882^{* *}$ & 1 & $0.973^{* *}$ & $0.308^{*}$ & $0.310^{*}$ & $0.748^{*}$ & $-0.278^{\mathrm{ns}}$ & $0.535^{*}$ \\
\hline FGWP & $0.842^{*}$ & 0.248 & $0.393^{\mathrm{ns}}$ & $0.442^{*}$ & $0.872^{*}$ & $0.971^{* *}$ & 1 & $0.353^{*}$ & $0.351^{*}$ & $0.750^{*}$ & $-0.284^{\mathrm{ns}}$ & $0.538^{*}$ \\
\hline 100GW & 0.281 & $0.976^{* *}$ & $0.16^{\mathrm{ns}}$ & $0.137^{\mathrm{ns}}$ & $0.320^{*}$ & 0.308 & $0.35^{*}$ & 1 & $0.999^{* * *}$ & $0.326^{*}$ & $-0.389^{n s}$ & $0.262^{\mathrm{ns}}$ \\
\hline $1000 \mathrm{GW}$ & $0.284^{* *}$ & $294^{* *}$ & $0.174^{\mathrm{ns}}$ & $0.145^{\mathrm{ns}}$ & $0.317^{* *}$ & $-0.309^{* *}$ & 0.348 & $0.999^{* *}$ & 1 & $0.323^{*}$ & $-0.390^{*}$ & $0.265^{\mathrm{ns}}$ \\
\hline FP & $0.845^{* *}$ & $258^{* *}$ & $04^{*}$ & $0.176^{\mathrm{ns}}$ & $0.812^{* *}$ & $0.745^{* *}$ & $0.737^{*}$ & $0.320^{* *}$ & $0.324^{* * *}$ & 1 & $-0.259^{\mathrm{ns}}$ & $0.224^{\mathrm{ns}}$ \\
\hline GC & $-0.297^{* *}$ & $-0.227^{*}$ & * & $-0.259^{* *}$ & $-0.294^{* *}$ & $-0.270^{* *}$ & $-0.255^{*}$ & $-0.352^{*}$ & $-0.379^{* *}$ & $-0.247^{* *}$ & 1 & $-0.355^{*}$ \\
\hline $\mathrm{B}$ & $0.402^{* *}$ & $0.437^{* *}$ & $0.437^{* *}$ & $0.953^{\text {** }}$ & $0.427^{* *}$ & $0.531^{* *}$ & $0.522^{*}$ & $0.253^{*}$ & $0.263^{* *}$ & $0.221^{*}$ & $-0.346^{* *}$ & 1 \\
\hline
\end{tabular}

ns, * and **: Non-significant, significant at $5 \%$ and $1 \%$ probability level, respectively

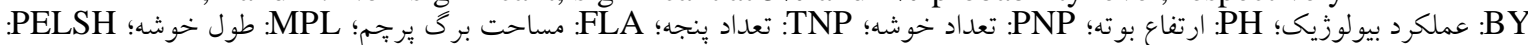

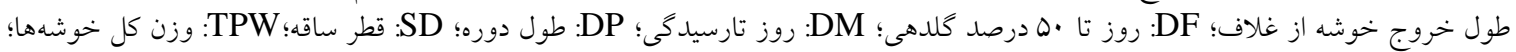

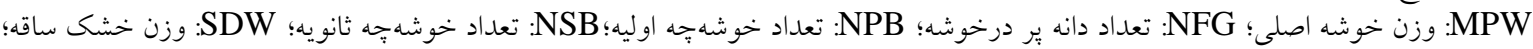

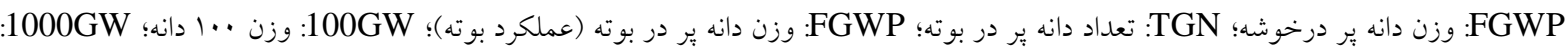

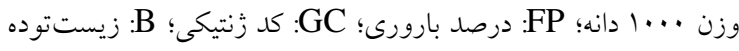

BY: Biological yield; PH: Plant height; PNP: Panicle number in plant; TNP: Tiller number in plant; FLA: Flag leaf area; MPL: The main panicle length; PELSH: The panicle exit length from sheath; DF: Days to 50\% flowering; DM: Daye's to maturity; DP: During the period; SD: Stem diameter; TPW: Total panicle weight; MPW: The main panicle weight; NFG: Number of filled grain in panicle; NPB: Number of primary branches; NSB: Number of Secondary branches; SDW: Stem dry weight; FGWP: Filled grain weight in panicle; TGN:

Total grain number in plant; FGWP: Filled grain weight in plant (grain yield); 100GW: 100 grain weight; 1000GW: 1000 grain weight; FP: Fertility percent; GC: Genotypic code; B: Biomass 
اصلى، طول خروج خوشه از غلاف، روز تا •ه درصد

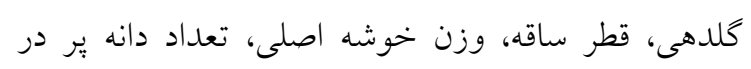

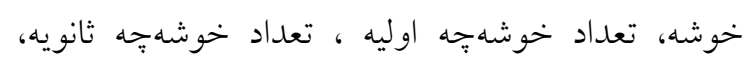

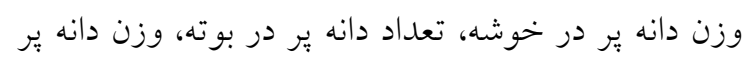

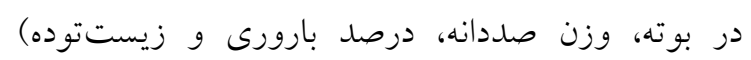

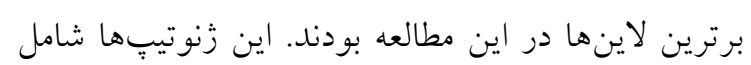

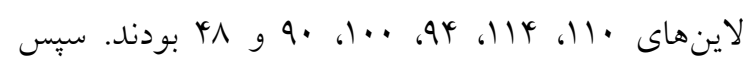
كروه جهارم داراى تعداد صفات بيشتر بالاترى از ميانخين

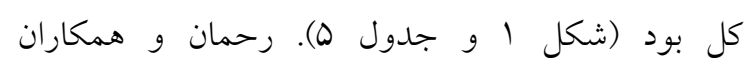

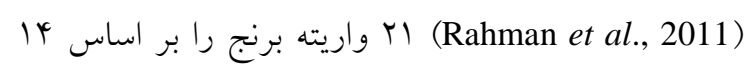

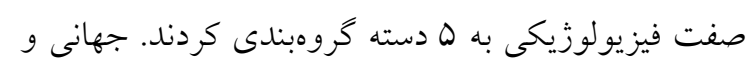

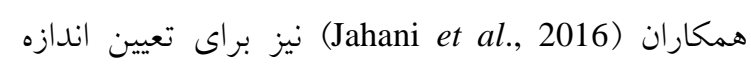

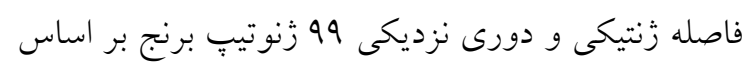

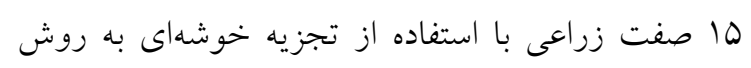

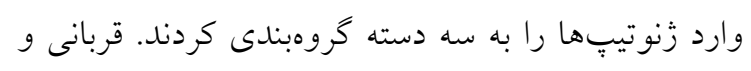

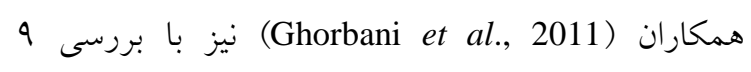

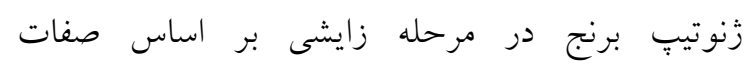

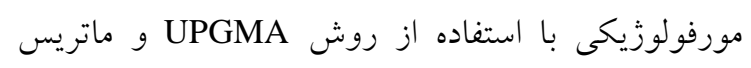

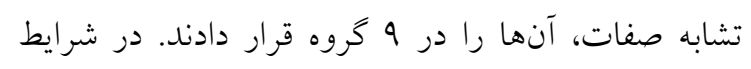

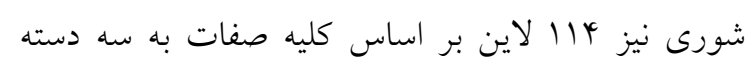

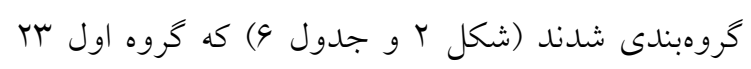

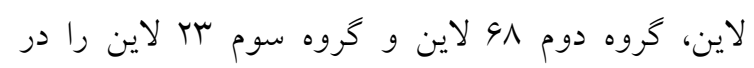

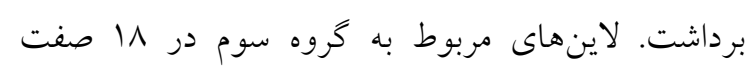

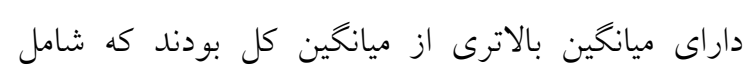
مقادير بالاتر صفات عملكرد و اجزاى عملكرد نيز بود.

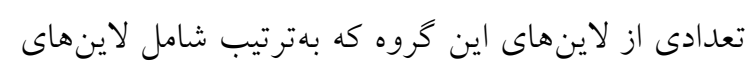

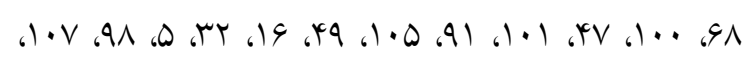
TV طول دوره رسيدكى و كد زنوتييى يايينى نيز داشتند (شكل

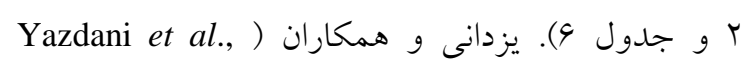
2014) نيز كه تجزيه خوشهاى را براى كروهبندى 90

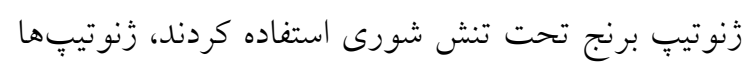
را در ب كروه قرار دادند.
همبستخى منفى زنوتييى و فنوتييى زيستتوده و كد

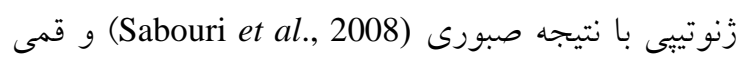

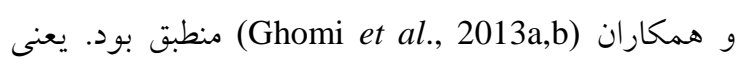
هرجهه زيستتوده بيشتر باشد كد كمتر وكياه متحملتر

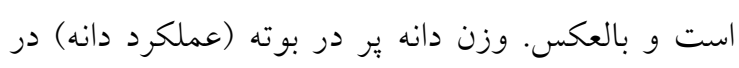

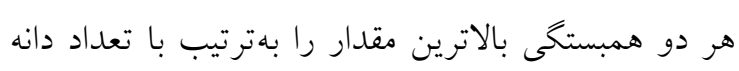

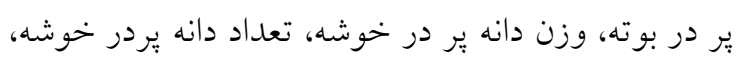

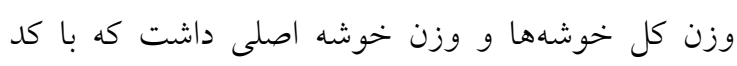
زنوتييى و طول دوره همبستخى منفى معنى دار داشت.

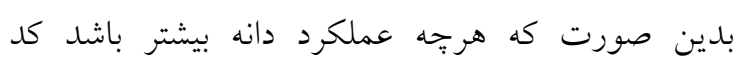
زنوتييى كمتر و كياهان متحمل تر خواهند بود. همرجنين اختر و همكاران (Akhtar et al., 2010) نيز بالاترين

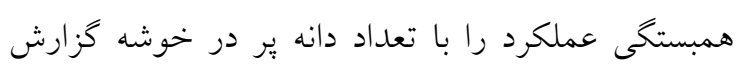
كردند. بخشبلوجزهى و كيانى ( Bakhsh-Balouchzaehi

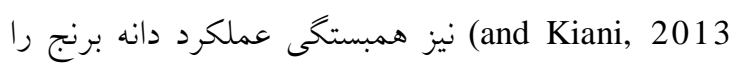

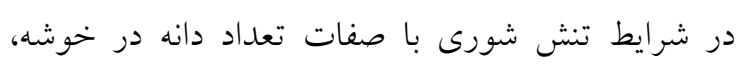

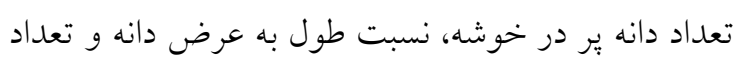

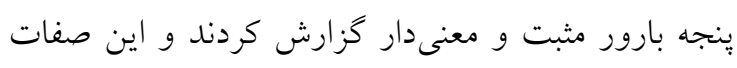
بيشترين نقش مثبت را در بهبود عملكرد دانه داشتند. هم:جنين همبستخى عرض دانه و وزن هزاردانه با عملكرد دانه منفى و معنى دار خزارش شد. همن.

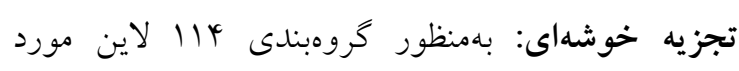
بررسى بر اساس كليه صفات مورد مطالعه، تجزيه

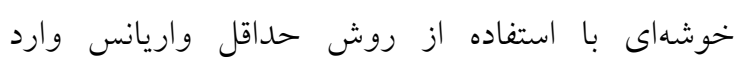

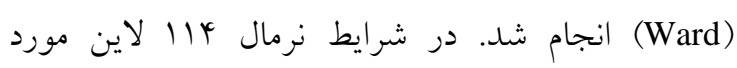
بررسى براى كليه صفات به جهار دسته كروهبندى شدند

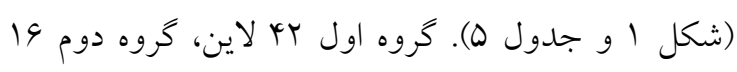

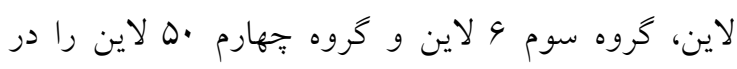
برداشت. هم جنين براى هر صفت ميانخين كل، ميانخين

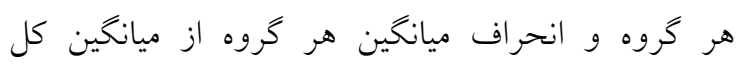

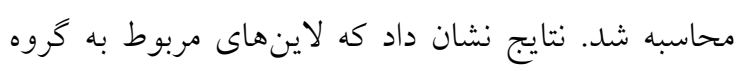
سوم بهعلت داشتن ميانكينى بيشتر از ميانخين كل براى 19

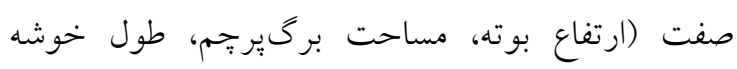


جدول ه- انحر اف ميانگين گروههاى ايجاد شده بر اساس كليه صفات از ميانگين كل در شرايط بدون تنش

Table 5. The mean deviation of groups created based on all of traits under normal (non-stress) condition

\begin{tabular}{|c|c|c|c|c|c|c|c|c|c|c|}
\hline صفات & Traits & $\begin{array}{c}\text { ميانگين كل } \\
\text { Total } \\
\text { average }\end{array}$ & $\begin{array}{c}\text { ميانگين گروه } 1 \\
\text { Average } \\
\text { group 1 }\end{array}$ & $\begin{array}{c}\text { انحراف ميانخين } 1 \\
\text { The mean } \\
\text { deviation group } 1\end{array}$ & $\begin{array}{l}\text { ميانخين گروه } \\
\text { Average } \\
\text { group 2 }\end{array}$ & $\begin{array}{c}\text { انحر اف ميانخين Y } \\
\text { The mean } \\
\text { deviation group } 2\end{array}$ & $\begin{array}{l}\text { Average group } \\
\text { ميانخين كروه } 1\end{array}$ & $\begin{array}{c}\text { انحراف ميانخين r } \\
\text { The mean } \\
\text { deviation group } 3\end{array}$ & $\begin{array}{l}\text { ميانخين گروه } \\
\text { Average } \\
\text { group 4 }\end{array}$ & $\begin{array}{c}\text { انحراف ميانخين } \\
\text { The mean } \\
\text { deviation group } 4\end{array}$ \\
\hline ارتفاع بوته & $\mathrm{PH}$ & 119.96 & $110.23^{\mathrm{a}}$ & -9.73 & $118.23^{\mathrm{ab}}$ & -1.73 & $129^{b}$ & 9.04 & $127^{\mathrm{b}}$ & 7.04 \\
\hline تعداد خوشه & PNP & 3.6 & $3.49^{\mathrm{a}}$ & -0.11 & $5.51^{\mathrm{b}}$ & 1.91 & $3.62^{\mathrm{a}}$ & 0.02 & $3.09^{\mathrm{a}}$ & -0.51 \\
\hline تعداد ينجه & TNP & 3.97 & $3.6^{\mathrm{a}}$ & -0.37 & $6.28^{\mathrm{b}}$ & 2.31 & $4.37^{\mathrm{a}}$ & 0.4 & $3.49^{\mathrm{a}}$ & -0.48 \\
\hline مساحت برگ ير جمم & FLA & 26.97 & $23.58^{\mathrm{a}}$ & -3.39 & $25.13^{\mathrm{ab}}$ & -1.84 & $30.73^{b}$ & 3.76 & $29.95^{\mathrm{b}}$ & 2.98 \\
\hline طول خوشه اصلى & LP & 24.31 & $22.28^{\mathrm{a}}$ & -2.03 & $24.27^{\mathrm{ab}}$ & -0.04 & $25.81^{\mathrm{b}}$ & 1.5 & $25.84^{\mathrm{b}}$ & 1.53 \\
\hline طول خروج خوشه & PELSH & 8.83 & $7.16^{\mathrm{ns}}$ & -1.67 & $10.5^{\mathrm{ns}}$ & 1.67 & $12.12^{\mathrm{ns}}$ & 3.29 & $9.3^{\mathrm{ns}}$ & 0.47 \\
\hline ينجاه درصد كلدهى & $\mathrm{DF}$ & 72.65 & $74.23^{b}$ & 1.58 & $66.81^{\mathrm{a}}$ & -5.84 & $77.62^{b}$ & 4.97 & $72.59^{a b}$ & -0.06 \\
\hline طول دوره رسيدگى & DP & 25.32 & $24.36^{\mathrm{a}}$ & -0.96 & $27.48^{\mathrm{b}}$ & 2.16 & $23.33^{\mathrm{a}}$ & -1.99 & $25.68^{\mathrm{ab}}$ & 0.36 \\
\hline قطر ساقه & $\mathrm{SD}$ & 5.43 & $5.29^{\mathrm{a}}$ & -0.14 & $5.12^{\mathrm{a}}$ & -0.31 & $6.34^{\mathrm{b}}$ & 0.91 & $5.54^{\mathrm{a}}$ & 0.11 \\
\hline وزن خوشه اصلى & MPW & 1.46 & $0.949^{\mathrm{a}}$ & -0.511 & $1.09^{\mathrm{a}}$ & -0.37 & $2.99^{\mathrm{c}}$ & 1.53 & $1.83^{\mathrm{b}}$ & 0.37 \\
\hline تعداد دانه بير & NFG & 53.44 & $35^{\mathrm{a}}$ & -18.44 & $33.09^{\mathrm{a}}$ & -20.35 & $112.62^{\mathrm{c}}$ & 59.18 & $68.34^{\mathrm{b}}$ & 14.9 \\
\hline تعداد خوشه اوليه & NPB & 8.47 & $7.95^{\mathrm{a}}$ & -0.52 & $7.69^{\mathrm{a}}$ & -0.78 & $11.45^{\mathrm{b}}$ & 2.98 & $8.81^{\mathrm{a}}$ & 0.34 \\
\hline تعداد خوشه ثانويه & NSB & 13.56 & $10.41^{\mathrm{a}}$ & -3.15 & $10.77^{\mathrm{a}}$ & -2.79 & $22.75^{\mathrm{c}}$ & 9.19 & $16^{\mathrm{b}}$ & 2.44 \\
\hline وزن دانه ير خوشه & FGWP & 1.23 & $0.753^{\mathrm{a}}$ & -0.477 & $0.728^{\mathrm{a}}$ & -0.502 & $2.59^{\mathrm{c}}$ & 1.36 & $1.63^{\mathrm{b}}$ & 0.4 \\
\hline تعداد دانه ير در بوته & TGNP & 99.03 & $54.1^{\mathrm{a}}$ & -44.93 & $82.37^{\mathrm{a}}$ & -16.66 & $254.12^{\mathrm{c}}$ & 155.09 & $123.5^{\mathrm{b}}$ & 24.47 \\
\hline وزن دانه ير در بوته & FGWP & 2.31 & $1.15^{\mathrm{a}}$ & -1.16 & $1.86^{\mathrm{a}}$ & -0.45 & $5.92^{c}$ & 3.61 & $3^{\mathrm{b}}$ & 0.69 \\
\hline وزن صددانه & 100GW & 2.34 & $2.22^{\mathrm{ns}}$ & -0.12 & $2.27^{\mathrm{ns}}$ & -0.07 & $2.49^{\mathrm{ns}}$ & 0.15 & $2.45^{\mathrm{ns}}$ & 0.11 \\
\hline درصد بارورى & FP & 54.57 & $45.5^{\mathrm{a}}$ & -9.07 & $41.31^{\mathrm{a}}$ & -13.26 & $73.53^{\mathrm{b}}$ & 18.96 & $66.69^{\mathrm{b}}$ & 12.12 \\
\hline زيست توده & GC & 15.92 & $12.36^{\mathrm{a}}$ & -3.56 & $22.99^{b}$ & 7.07 & $25.47^{\mathrm{b}}$ & 9.55 & $15.5^{\mathrm{a}}$ & -0.42 \\
\hline
\end{tabular}

Means with different letters are significantly different at 0.05 probability level. 


\begin{tabular}{|c|c|c|c|c|c|c|c|c|}
\hline \multicolumn{9}{|c|}{$\begin{array}{l}\text { جدول 9- انحراف ميانخين گروههاى ايجاد شده براساس كليه صفات از ميانخين كل در شرايط تنش شورى } \\
\text { Table 6. The mean deviation of groups created based on all of traits under salt stress condition }\end{array}$} \\
\hline صفات & Traits & $\begin{array}{c}\text { ميانخين كل } \\
\text { Total } \\
\text { average }\end{array}$ & $\begin{array}{c}\text { ميانخين گروه } \\
\text { Average } \\
\text { group 1 }\end{array}$ & $\begin{array}{c}\text { انحراف ميانگين } 1 \\
\text { The mean } \\
\text { deviation group } 1\end{array}$ & $\begin{array}{c}\text { ميانگين گروه } \\
\text { Average } \\
\text { group 2 }\end{array}$ & $\begin{array}{c}\text { انحر اف ميانگين } \\
\text { The mean } \\
\text { deviation group } 2\end{array}$ & $\begin{array}{c}\text { ميانگين گروه } \\
\text { Average } \\
\text { group 3 }\end{array}$ & $\begin{array}{c}\text { انحراف ميانخين } \\
\text { The mean } \\
\text { deviation group } 3\end{array}$ \\
\hline ارتفاع بوته & $\mathrm{PH}$ & 91.71 & $73.83^{\mathrm{a}}$ & -17.88 & $92.71^{\mathrm{b}}$ & 1 & $106.61^{\mathrm{c}}$ & 14.9 \\
\hline تعداد خوشه & PNP & 2.79 & $1.63^{\mathrm{a}}$ & -1.16 & $3.02^{\mathrm{b}}$ & 0.23 & $3.29^{\mathrm{b}}$ & 0.5 \\
\hline تعداد ينجه & TNP & 3.53 & $3.18^{\mathrm{ns}}$ & -0.35 & $3.64^{\mathrm{ns}}$ & 0.11 & $3.55^{\mathrm{ns}}$ & 0.02 \\
\hline مساحت برگ برجم & FLA & 17.04 & $12.09^{\mathrm{a}}$ & -4.95 & $17.08^{\mathrm{b}}$ & 0.04 & $21.85^{\mathrm{c}}$ & 4.81 \\
\hline طول خوشه اصلى & LP & 17.92 & $12.8^{\mathrm{a}}$ & -5.12 & $18.45^{\mathrm{b}}$ & 0.53 & $21.39^{c}$ & 3.47 \\
\hline طول خروج خوشه & PELSH & 3.28 & $1.1^{\mathrm{a}}$ & -2.18 & 2.53 & -0.75 & 7.68 & 4.4 \\
\hline ينجاه درصد گلدهى & DF & 79.49 & $82.19^{b}$ & 2.7 & $77.43^{\mathrm{a}}$ & -2.06 & $82.9^{\mathrm{b}}$ & 3.41 \\
\hline طول دوره & DP & 16.91 & $15.54^{\mathrm{ab}}$ & -1.37 & $17.95^{\mathrm{b}}$ & 1.04 & $15.22^{\mathrm{a}}$ & -1.69 \\
\hline قطر ساقه & SD & 4.6 & $4.32^{\mathrm{a}}$ & -0.28 & $4.55^{\mathrm{ab}}$ & -0.05 & $5.02^{\mathrm{b}}$ & 0.42 \\
\hline وزن خوشه اصلى & MPW & 0.463 & $0.183^{\mathrm{a}}$ & -0.28 & $0.375^{\mathrm{b}}$ & -0.088 & $1^{\mathrm{c}}$ & 0.537 \\
\hline تعداد دانه ير در خوشه & NFG & 14.85 & $1.98^{\mathrm{a}}$ & -12.87 & $9.87^{\mathrm{b}}$ & -4.98 & $42.45^{\mathrm{b}}$ & 27.6 \\
\hline تعداد خوشه بِه اوليه & NPB & 6.58 & $4.61^{\mathrm{a}}$ & -1.97 & $6.73^{\mathrm{b}}$ & 0.15 & $8.09^{\mathrm{c}}$ & 1.51 \\
\hline تعداد خوشه بحه ثانويه & NSB & 6.44 & $3.56^{\mathrm{a}}$ & -2.88 & $5.89^{\mathrm{b}}$ & -0.55 & $10.94^{\mathrm{c}}$ & 4.5 \\
\hline وزن دانه ير در خوشه & FGWP & 0.265 & $0.025^{\mathrm{a}}$ & -0.24 & $0.1728^{\mathrm{b}}$ & -0.0922 & $0.781^{\mathrm{c}}$ & 0.516 \\
\hline تعداد دانه ير در بوته & TGNP & 22.92 & $2.38^{\mathrm{a}}$ & -20.54 & $15.34^{\mathrm{b}}$ & -7.58 & $66.21^{\mathrm{c}}$ & 43.29 \\
\hline وزن دانه يֶ در بوته & FGWP & 0.416 & $0.033^{\mathrm{a}}$ & -0.383 & $0.269^{b}$ & -0.147 & $1.234^{\mathrm{c}}$ & 0.818 \\
\hline وزن صددانه & 100GW & 1.565 & $0.677^{\mathrm{a}}$ & -0.888 & $1.766^{\mathrm{b}}$ & 0.201 & $1.86^{\mathrm{b}}$ & 0.295 \\
\hline درصد بارورى & FP & 22.19 & $6.21^{\mathrm{a}}$ & -15.98 & $18.31^{\mathrm{b}}$ & -3.88 & $49.66^{\mathrm{c}}$ & 27.47 \\
\hline كد زنوتيبى & GC & 4.4 & $6.3^{c}$ & 1.9 & $4.24^{\mathrm{b}}$ & -0.16 & $3^{\mathrm{a}}$ & -1.4 \\
\hline زيست توده & B & 8.91 & $5.95^{\mathrm{a}}$ & -15.98 & $8.61^{\mathrm{b}}$ & -3.88 & $12.76^{\mathrm{c}}$ & 27.47 \\
\hline
\end{tabular}


بُوهشهاى زنتيك گياهى / جلد 9 / شماره | / 19ه|

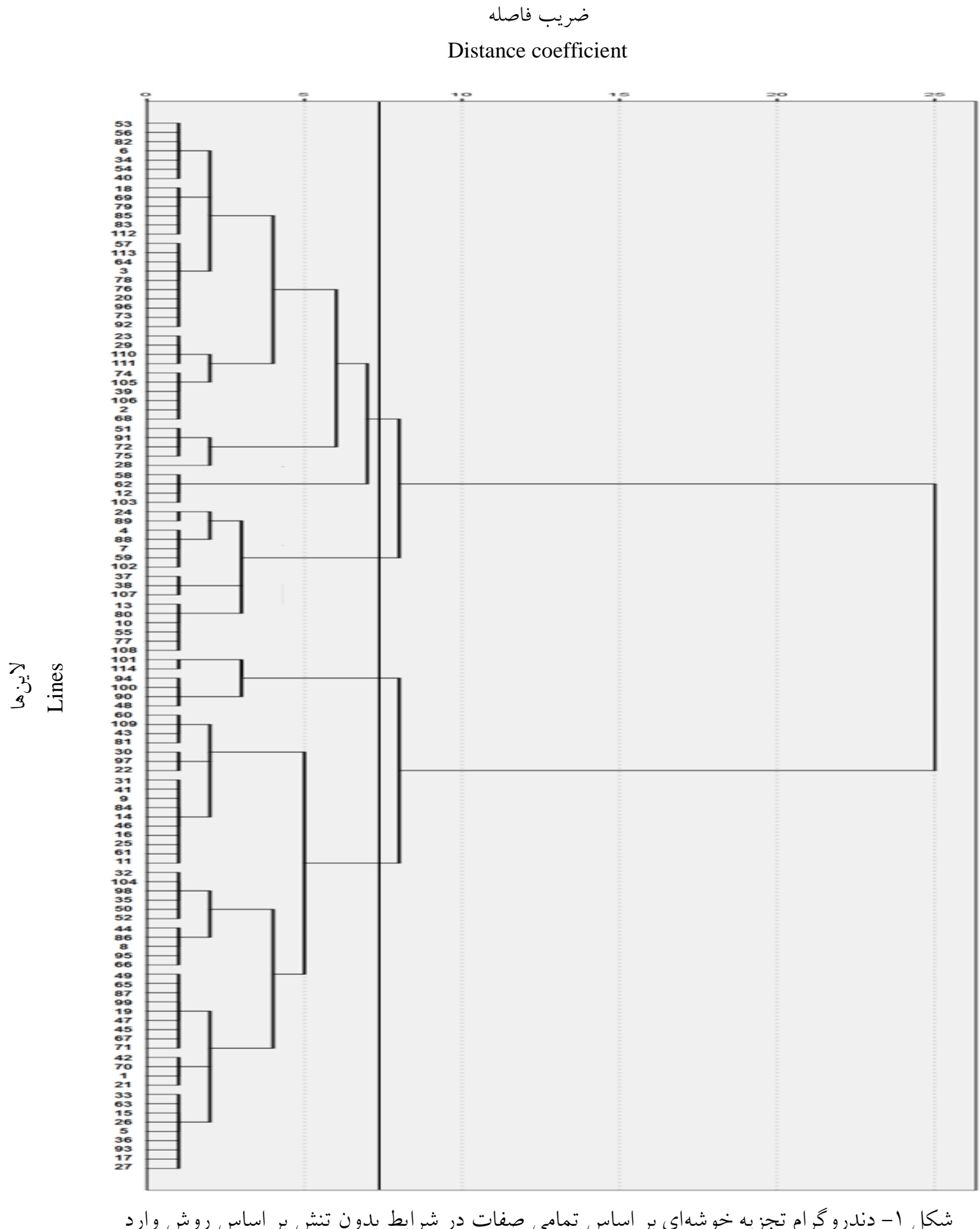

Figure 1. Dendrogram of cluster analysis on all traits in normal condition based on ward method 


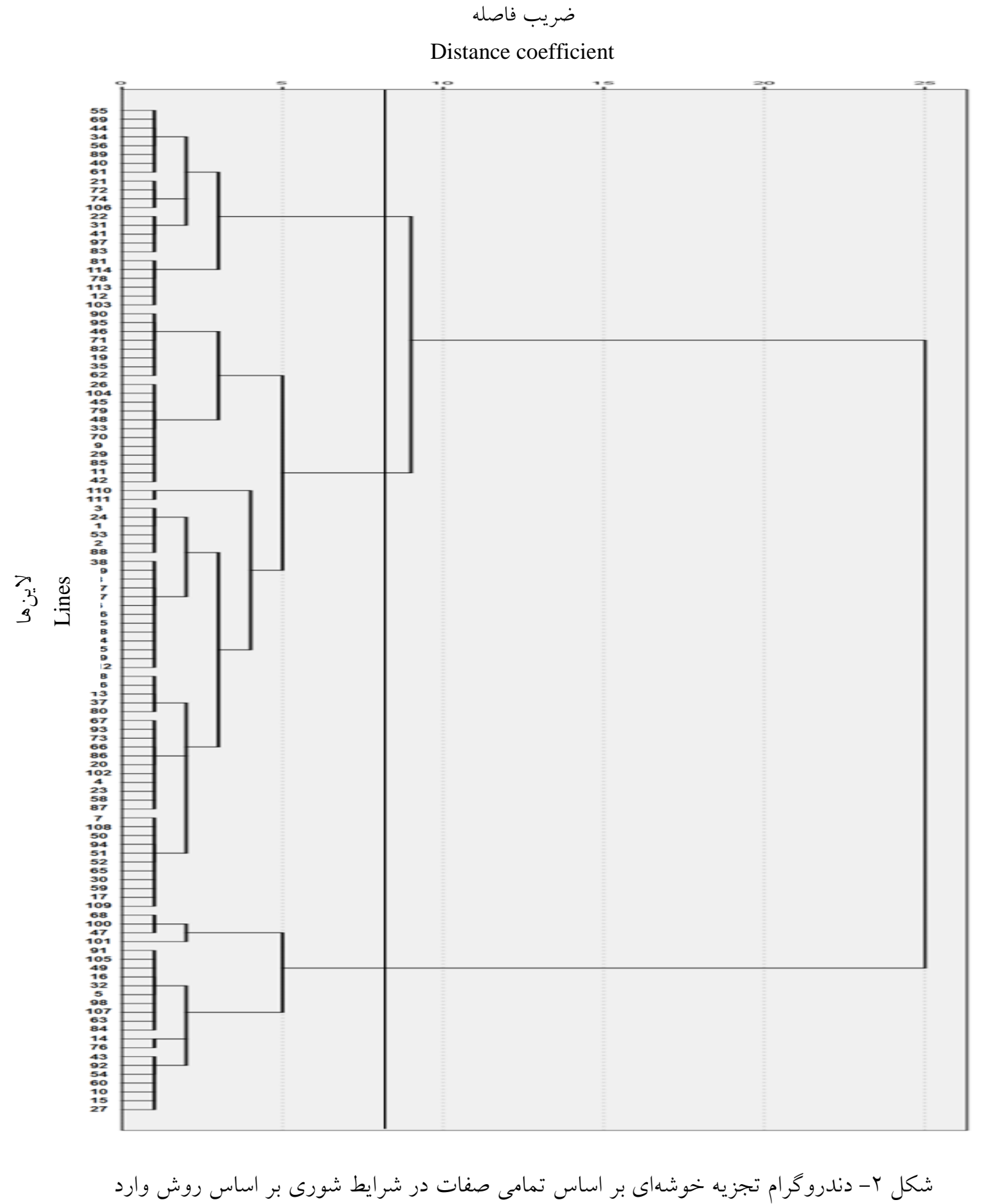

Figure 2. Dendrogram of cluster analysis on all traits in salt stress condition based on ward method

صفات تعداد دانه ير در بوته و خوشه بهعنوان مهــمترين صفات مؤثر بر عملكرد دانه و انتخاب براى توسعه لاينهاى با بازده عملكرد بالا در شرايط مزرعه مىتواند مهم باشد. در شرايط نرمال لاينهاى ·لإ،

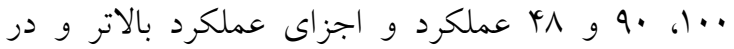

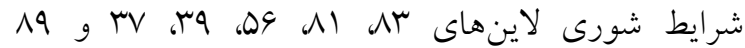
بنابراين نتايج حاصل از اين يزوهش نشان داد كه

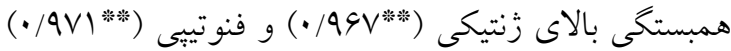
عملكرد دانه (وزن دانه ير در بوته) با تعداد دانه ير در بوته در شرايط نرمال و نيز همبستكى زنتيكى ("9V/•")

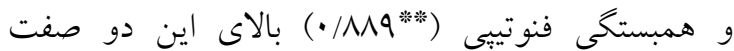
تحت شرايط تنش وجود داشت. با توجه به تحقيق حاضر 


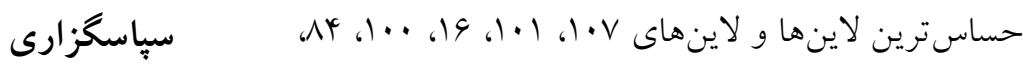

$$
\begin{aligned}
& \text { بلدينوسيله از مسئولان محترم دانشكده كشاورزى دانشخاه } \\
& \text { كيلان، گروه بيوتكنولوزى و دانشكده كشاورزى دانشخاه } \\
& \text { كنبد كاووس بابت همكارى و هماهنكى هاى مربوطه } \\
& \text { سياسگزارى مىشود. }
\end{aligned}
$$

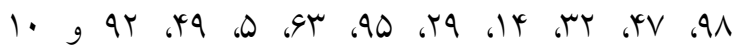

$$
\begin{aligned}
& \text { متحمل ترين لاينها به تنش شورى هشت دسىزيمنس بر } \\
& \text { متر بودند و عملكرد و اجزاى عملكرد بالاترى داشتند. } \\
& \text { لاينهاى متحمل مستقيماً جهت كشت در مزارع شور و يا } \\
& \text { جهت انتقال تحمل به شورى به ارقام تجارى از طريت } \\
& \text { برنامههاى اصلاحى آينده بيشنهاد مىشوند. }
\end{aligned}
$$

\section{References}

Abdmishani, S. and Shahnejat-Bushehri, A.A. (1997). Advanced Plant Breeding. University of Tehran Press, Tehran, IR (In Persian).

Akbar, M., Gunawardena, I.E. and Ponnamperuma, F.N. (1986). Breeding for Soil Stresses. Progress in Rainfed Lowland Rice. IRRI, Los Baños. PH.

Akhtar, S., Islam, M.M., Begum, S.N., Halder, J., Alam, M.K. and Manidas, A.C. (2010). Genetic analysis of $\mathrm{F}_{4}$ rice lines for salt tolerance at the reproductive stage. Agricultoral, 21(1 \& 2): 31-38.

Aref, F. and Ebrahimi Rad, H. (2012). Physiological characterization of rice under salinity stress during vegetative and reproductive stages. Indian Journal of Science and Technology. 5(4): 09746846.

Bakhsh-Balouchzaehi, A. and Kiani, G. (2013). Determination of selection criteria for yield improvement in rice through path analysis. Journal of Crop Breeding, 5: 75-84 (In Persian).

Ebrahimi, M.A., Mohammadian, R. and Khalili, M. (2016). Estimation of genetic correlation, heritability and grouping of barley doubled haploid lines based on indicators related to germination under salt stress. Plant Genetic Researches, 3(1): 29-44 (In Persian).

FAO. (2016). Food and Agriculture Organization, FAO statistic. http://www.fao.org/faostat/en/\#data/ QC. Accessed 26 June 2016

Fentie, D., Alemayehu, G., Siddalingaiah, M. and Tadesse, M. (2014). Genetic variability, heritability and correlation coefficient analysis for yield and yield component traits in upland rice (Oryza sativa L.). East African Journal of Sciences, 8(2): 147-154.

Garris, A.J., Tai, T.H., Coburn, J., Kresovich, S. and McCouch, S. (2005). Genetic structure and diversity in Oryza sativa L. Genetics, 169: 1631-1638.

Ghomi, K., Rabiei, B., Sabouri, H. and Sabouri, A. (2013a). Mapping QTLs for traits related to salinity tolerance at seedling stage of rice (Oryza sativa L.): An agrigenomics study of an Iranian rice population. OMICS: A Journal of Integrative Biology, 17(5): 242-251.

Ghomi, K., Rabiei, B., Sabouri, H. and Sabouri, A. (2013b). Evaluation of seedling stage and identification of appropriate selection criteria in an rice segregating population (Oryza sativa L.) under salinity stress condition. Journal of Crop Breeding, 5(1): 30-48 (In Persian).

Ghorbani, H., Samizadeh-Lahiji, H.A., Rabiei, B. and Allahgholipour, M. (2011). Grouping different rice genotypes using factor and cluster analysis. Journal of Agricultural Science. 3: 89104 (In Persian).

Gilroy, S., Suzuki, N. and Miller, G. (2014). A tidal wave of signals: calcium and ROS at the forefront of rapid systemic signaling. Trends in Plant Science, 19: 623-630.

Gohari, M., Khayat, M. and Lack, S.H. (2010). Correlation relation and path coefficient analysis effective agronomic traits evolution on seed yield of rice (Oryza Sativa L.) cultivar. Journal of Agricultural New Findings, 3: 261-269 (In Persian).

Golparvar, A.R., Ghanadha, M.R., Zali, A.A. and Ahmadi, A. (2003). Evaluation of some morphological traits as selection criteria in breeding wheat. Iranian Journal of Crop Sciences, 4(3): 202-208 (In Persian). 
Gregorio, G.B., Senadhira, D. and Mendoza, R.D. (1997). Screening Rice for Salinity Tolerance. IRRI 502 Discussion Paper Series No. 22. International Rice Research Institute, Los Baños, PH.

Honarnejad, R. (2002). Study of correlation between some quantitative traits and grain yield in rice (Oryza sativa L.) using path analysis. Journal of Iranian Crop Science, 1: 25-33 (In Persian).

Hossain, S., Maksudu, H.M.D. and Rahman, J. (2015). Genetic variability, correlation and path coefficient analysis of morphological traits in some extinct local aman Rice (Oryza sativa L). Journal Rice Resource, 3: 158. doi:10.4172/2375-4338.1000158.

Islam, M.Z., Khalequzzaman, M., Bashar, M.K., Ivy, N.A., Haque, M.M. and Mian, M.A.K. (2016). Variability assessment of aromatic and fine rice germplasm in Bangladesh based on quantitative traits. The Scientific World Journal, 2016: 2796720. http://dx.doi.org/10.1155/2016/ 2796720

Jahani, M., Nematzade, G. and Mohammadi-Nejad, G.H. (2016). Assessment of genetic diversity in rice varieties with desirable agronomic characteristics. Journal of Crop Production, 9(1): 181198 (In Persian).

Konate, A.K., Zongo, A., Kam, H., Sanni, A., and Audebert, A. (2016). Genetic variability and correlation analysis of rice (Oryza sativa) inbred lines based on agromorphological traits. African Journal of Agricultural Research, 11(35): 3340-3346.

Kordrostami, M., Rabiei, B. and Hassani Kumleh, H. (2017). Different physiobiochemical and transcriptomic reactions of rice (Oryza sativa L.) cultivars differing in terms of salt sensitivity under salinity stress. Environmental Science \& Pollution Research, 24: 7184-7196.

Mirdar-Mansouri, S.H., Babaiyan Golodar, N. and Bagheri, N. (2014). Effects of NaCl Stress on Grain Yield and their Components in Iranian Rice Genotypes. Journal of Crop Breeding, 6(14): 67-83 (In Persian).

Mohammadzadeh, M., Peyghambari, S.A., Nabipour, A. and Norouzi, M. (2010). Evaluating of yield and morphological characters in tolerance and sensitive genotypes to salinity stress in rice (Oryza sativa L.). Journal of Planting and Plant Amending, 6(4): 61-71 (In Persian).

Munns, R. and Tester, M. (2008). Mechanisms of salinity tolerance. Annual Review of Plant Biology, 59: 651-681.

Mahdavi, F., Esmaili, M.A., Pirdashti, H. and Fallah, A. (2003). Study on the Physiological and morphological indices among the modern and old rice (Oryza sativa L.) genotypes. $4^{\text {th }}$ International Crop Science Congress. Brisbane, Queensland, AU.

Mahmood, N. and Cowdhry, M.A. (2000). Inheritance of flag leaf in breed wheat genotypes. Wheat Information Service (WIS), 90: 7-12.

Mer, R.K., Prajith, P.K., Pandya, D.H. and Dandey, A.N. (2000). Growth of young plants of Hordeum Vulgare, Triticum aestivum, Cicer arienum and Brassica Juncea. Journal Agronomy and Crop Science, 185: 209-217.

Maas, E.V. and Hoffmann, G.J. (1977). Crop salt tolerance-current assessment. Journal of the Irrigation and Drainage Division, 103: 115-134.

Rahman, M.M., Rasul, M.G., Bashar, M.K., Syed, M.A. and Islam, M.R. (2011). Parent selection for transplanted aman rice breeding by morphological, physiological and molecular diversity analysis. Libyan Agriculture Research Center Journal International, 2: 26-28.

Rashid, M.M., Hassan, L. and Begum S.N. (2017). Phenotypic performance of rice landraces under salinity stress in reproductive stage. Progressive Agriculture, 28(1): 1-6.

Sabouri, H., Rezai, A.M. and Moumeni, A. (2008). Evaluation of salt tolerance in Iranian landrace and improved rice cultivars. Journal of Science and Technology of Agriculture and Natural Resources, 45: 47-63 (In Persian).

Sabouri, H. and Biabani, A. (2009). Toward the mapping of agronomic characters on rice genetic map: QTL analysis under saline condition. Biotechnology, 8: 144-149. 
Savitha, P. and Usha-Kumari, R. (2015). Assessment of genetic variability and correlation studies among traditional land races and improved cultivars for segregating generations of rice (Oryza sativa L.). International Journal of Science and Nature, 6(2): 135-140.

Venkata-Lakshmi, M., Suneetha, Y., Yugandhar, G. and Venkata-Lakshmi, N. (2014). Correlation studies in rice (Oryza sativa L.). International Journal of Genetic Engineering Biotechnology, 5(2): 121-126.

Yoshida, S., Bhattacharjee, D.P. and Cabuslay, G.S. (1982). Relationship between plant type and root growth in rice. Soil Science and Plant Nutrition, 28(4): 473-482.

Yazdani, M., Kochak, M. and Bagheri, H. (2014). Segregating rice genotypes by cluster analysis procedure at different salt stress condition. Advances Environment Biology, 8(10): 383-387. 


\title{
Genetic Diversity of Iranian Rice Recombinant Inbred Lines at the Reproductive Stage in Normal and Salinity Conditions
}

\author{
Seyede Minoo Mirarab Razi ${ }^{1}$, Reza Shirzadian-Khorramabad ${ }^{2, *}$, Hossein Sabouri ${ }^{3}$, \\ Babak Rabiei $^{4}$ and Hossein Hosseini Moghadam ${ }^{5}$
}

1- Ph.D. Student, Department of Biotechnology, University Campus 2, University of Guilan, Rasht, Iran

2- Associate Professor, Department of Biotechnology, Faculty of Agricultural Sciences, University of Guilan, Rasht, Iran

3- Associate Professor, Department of Plant Production, Gonbad University, Faculty of Agriculture Science and Natural Resource, Gonbad, Iran

4- Professor, Department of Agronomy and Plant Breeding, Faculty of Agricultural Sciences, University of Guilan, Rasht, Iran

5- Assistant Professor, Department of Plant Production, Faculty of Agriculture Science and Natural Resource, Gonbad University, Gonbad, Iran

(Received: July 6, 2017 - Accepted: November 28, 2017)

\begin{abstract}
Salinity is an important limiting factor in the production of more plants, including rice. Due to the limited amount of cultivated area, identification of tolerant genotypes to environmental stresses and especially salinity is very important. The aim of this study was to investigate the genetic diversity among 114 recombinant lines derived from the intersection of local Tarom $\times$ Khazar cultivars under non stress conditions and salinity levels of $8 \mathrm{dS} / \mathrm{m}$ in reproductive stage in a completely randomized design. Combined analysis of variance showed that the differences between lines was significant for all traits. Genotypic variation coefficients also showed that the highest genetic variation among the evaluated recombinant lines was related to the number of panicles per plant. In contrast, days to $50 \%$ flowering showed the least genetic variation among these lines. In non stress and stress conditions, the highest genotypic and phenotypic correlation coefficient was observed between grain yield and number of fill grain in seedlings. Based on the cluster analysis of grain yield, the lines were classified into four groups under normal conditions and were classified into three groups under salinity conditions. The third-party lines in both cases had a higher average than the overall average. In general, the results of this study showed that there is a significant genetic variation between the studied lines in terms of salt tolerance and this variety can be used in subsequent corrective programs. Accordingly, lines 83, 81, 56, 39, 37 and 89 were the most sensitive lines and lines 107, 101, 16, 100, $84,98,47,32,14,29,95,63,5,49,92$ and 10 were the most tolerant lines to salinity stresses of 8 $\mathrm{dS} / \mathrm{m}$ and they also had higher yields and yield components. Strained lines are proposed directly for cultivating saline or for transferring salt tolerance to commercial cultivars through future breeding programs.
\end{abstract}

Keywords: Rice, Cluster analysis, Correlation, Factor analysis, Salinity

\footnotetext{
*Corresponding Author, E-mail: r.shirzadian@guilan.ac.ir
} 